\title{
A Mechanistic Approach to Understanding the Factors Affecting Drug Absorption: A Review of Fundamentals
}

\author{
Marilyn N. Martinez, PhD, and Gordon L. Amidon, PhD
}

\begin{abstract}
This article provides an overview of the patient-specific and drug-specific variables that can affect drug absorption following oral product administration. The oral absorption of any chemical entity reflects a complex spectrum of events. Factors influencing product bioavailability include drug solubility, permeability, and the rate of in vivo dissolution. In this regard, the Biopharmaceutics Classification System has proven to be an important tool for predicting compounds likely to be associated with bioavailability problems. It also helps in identifying those factors that may alter the rate and extent of drug absorption. Product bioavailability can also be markedly influenced by patient attributes such as the integ-
\end{abstract}

rity of the gastrointestinal tract, physiological status, site of drug absorption, membrane transporters, presystemic drug metabolism (intrinsic variables), and extrinsic variables such as the effect of food or concomitant medication. Through an awareness of a drug's physicochemical properties and the physiological processes affecting drug absorption, the skilled pharmaceutical scientist can develop formulations that will maximize product availability. By appreciating the potential impact of patient physiological status, phenotype, age, gender, and lifestyle, dosing regimens can be tailored to better meet the needs of the individual patient.

Journal of Clinical Pharmacology, 2002;42:620-643 C2002 the American College of Clinical Pharmacology
A fundamental premise associated with the use of a therapeutic agent is that for any given patient, the clinical response can be predicted on the basis of the selected drug product, dose, and dosing regimen. This tenet provides the foundation for concepts of prescribability and switchability. ${ }^{1}$ Prescribability refers to an assumed relationship between a therapeutic outcome and the rate and extent of drug exposure. A physician will prescribe a particular product in accordance with assumptions pertaining to this relationship.

Generally, the process of drug movement from intake (e.g., oral delivery systems) to its site of action can be schematically presented as follows (Figure 1).

As depicted in Figure 1, the relationship between drug intake and a clinical response is highly complex, potentially affected by a host of intrinsic and extrinsic

From the Office of New Animal Drug Evaluation, HFV-130, Center for Veterinary Medicine, Food and Drug Administration, Rockville, Maryland (Dr. Martinez) and the University of Michigan, College of Pharmacy, Ann Arbor, Michigan (Dr. Amidon). Submitted for publication August 15, 2001; revised version accepted February 15, 2002. Address for reprints: Marilyn N. Martinez, Office of New Animal Drug Evaluation, HFV-130, Center for Veterinary Medicine, Food and Drug Administration, 7500 Standish Place, Rockville, MD 20855. variables. Accordingly, deviations between drug response within or between individuals may be ascribed either to product bioavailability (i.e., the rate and extent of drug absorption), drug pharmacokinetics (which includes the metabolism, distribution, and elimination of a compound), or the particular concentration-effect relationship.

While product formulation can significantly affect processes leading to drug absorption, once in the circulation, the original formulation is generally considered to no longer affect the ultimate drug response. In other words, it is the concentration of the drug moiety, along with its corresponding effect, that will ultimately determine product safety and effectiveness. For this reason, once a patient is titrated to a particular product and dosing regimen, we assume that a comparable clinical response will be achieved if the patient elects to take a less expensive generic equivalent.

The purpose of this article is to discuss basic principles associated with the process of drug absorption. Special attention will be given to the use of the Biopharmaceutics Classification System (BCS) as a predictive tool for identifying compounds whose absorption characteristics may be sensitive to intrinsic 


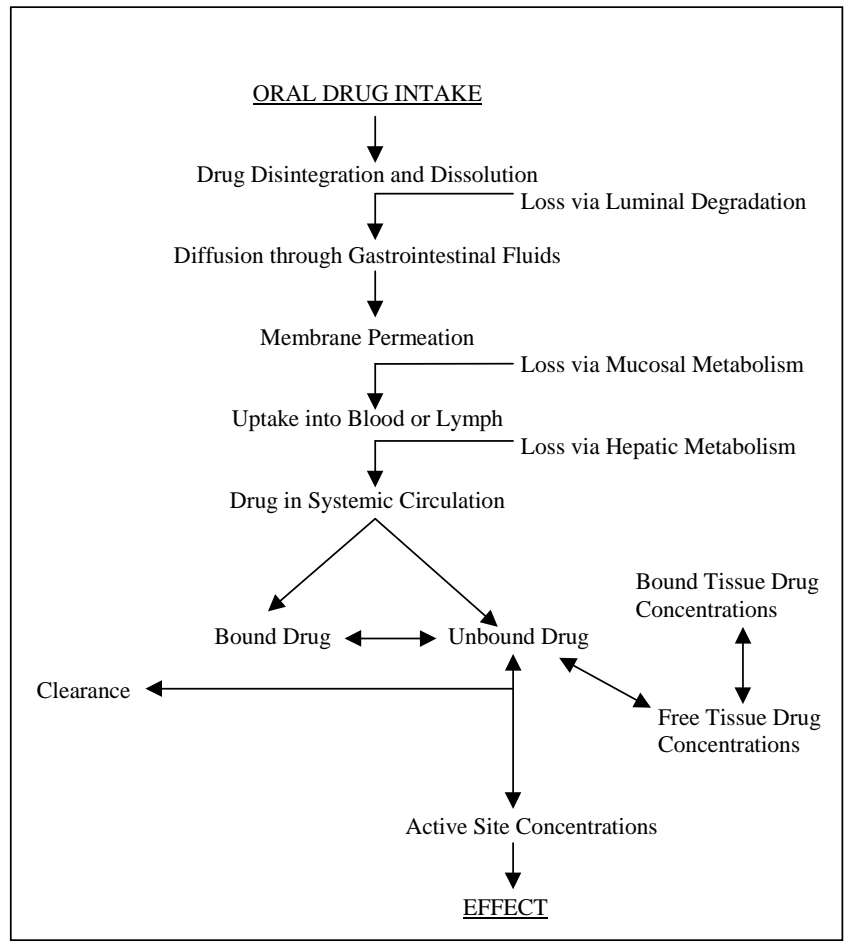

Figure 1. Schematic diagram of the relationship between an oral dose of a drug product and its ultimate effect.

(physiological) and extrinsic (e.g., food and formulation) variables. Accordingly, this review focuses on those factors that can affect drug dissolution, aqueous solubility, membrane permeability, and presystemic drug metabolism.

\section{WHAT IS THE BCS?}

One of the most significant prognostic tools created to facilitate product development in recent years has been the BCS. ${ }^{2}$ By knowing the solubility and permeability characteristics of specific compounds, we improve our ability to predict those variables (such as formulation, food, dosing regimen, and disease) that will alter oral drug absorption.

Currently, all pharmaceutical compounds are grouped into one of the following categories:

Class I-high solubility, high permeability: generally very well-absorbed compounds

Class II-low solubility, high permeability: exhibit dissolution rate-limited absorption

Class III-high solubility, low permeability: exhibit permeability rate-limited absorption
Class IV_low solubility, low permeability: very poor oral bioavailability

Solubility is calculated on the basis of the largest strength manufactured. It is defined as the minimum solubility of drug across a $\mathrm{pH}$ range of 1 to 8 and at a temperature of $37 \pm 0.5^{\circ} \mathrm{C}$. High-solubility drugs are those with a ratio of dose to solubility volume that is less than or equal to $250 \mathrm{ml}$. Permeability $\left(\mathrm{P}_{\text {eff }}\right.$, expressed in units of $10^{4} \mathrm{~cm}$ per second) is defined as the effective human jejunal wall permeability of a drug. High-permeability drugs are generally those with an extent of absorption greater than or equal to $90 \%$ and are not generally associated with any documented instability in the gastrointestinal tract.

It is interesting to note that for certain compounds, $\mathrm{P}_{\text {eff }}$ is not necessarily constant. For example, nonlinear changes in $\mathrm{P}_{\text {eff }}$ were observed with increasing doses of the surface-active molecule, fluvastatin. This nonlinear increase in $\mathrm{P}_{\text {eff }}$ was attributed to its effects on membrane surface tension and to a possible decrease in poly-glycoprotein (P-gp) activity associated with an increase in intestinal membrane fluidity. ${ }^{3}$

The application of this system to nonhuman species may require adjustment of these classification parameters based on physiological differences in gastric volume and the $\mathrm{pH}$ of the gastrointestinal (GI) fluids. Accordingly, at this time, we cannot be certain that the BCS classification of a compound remains constant across all species. This question is currently being explored by the Food and Drug Administration's (FDA's) Center for Veterinary Medicine.

By understanding the relationship between a drug's absorption, solubility, and dissolution characteristics, it is possible to define situations when in vitro dissolution data can provide a surrogate for in vivo bioequivalence assessments. The use of this surrogate relies on the validity of three fundamental assumptions. First, it must be assumed that a comparison of product in vitro dissolution performance accurately reflects relative differences in product in vivo dissolution behavior. Second, we must assume that if two products present with equivalent in vivo dissolution profiles under all luminal conditions, they will present equivalent drug concentrations at absorptive membrane surfaces. Third, for comparable dissolution profiles to ensure comparable in vivo absorption, the rate and extent of drug presented to absorptive membrane surfaces must determine the absorption characteristics of that drug product.

Lobenberg and Amidon ${ }^{4}$ have summarized the relationships between dose, dissolution characteristics, drug solubility, and drug absorption properties. These relationships can be described as follows: 
1. Absorption number $(\mathrm{An})=\left(\mathrm{P}_{\text {eff }} / \mathrm{R}\right) \bullet<\mathrm{Tsi}>$,

where $\mathrm{R}$ is the gut radius and $<\mathrm{Tsi}>$ the residence time of the drug within the intestine.

2. Dissolution number $(\mathrm{Dn})=\left(3 \mathrm{D} / \mathrm{r}^{2}\right) \bullet\left(\mathrm{C}_{\mathrm{s}} / \rho\right) \bullet<\mathrm{Tsi}>$,

where $\mathrm{D}$ is the diffusivity of the dissolved drug, $\rho$ is the density of the dissolved drug, $\mathrm{C}_{\mathrm{s}}$ is the drug solubility, and $\mathrm{r}$ is the initial radius of the drug particle.

3. Ratio of dose to dissolved drug $\left(D_{0}\right)=\frac{M / V_{0}}{C_{s}}$,

where $\mathrm{M}$ is the dose of the drug and $\mathrm{V}_{0}$ is the volume of fluid consumed with the dose.

The fraction of drug absorbed is closely related to the drug's effective permeability across mucosal cells. ${ }^{4}$ If the $\mathrm{P}_{\text {eff }}$ of a drug is less than $2 \bullet 10^{-4} \mathrm{~cm} / \mathrm{s}$, then drug absorption will be incomplete, whereas complete absorption can be expected for substances whose $\mathrm{P}_{\text {eff }}$ exceeds this value. For poorly soluble drugs, critical variables include the volume of the intestinal fluids, GI pH, and GI transit time (where adequate time is needed to dissolve poorly soluble materials). For these lipophilic compounds, food and bile salts may increase drug solubility.

Class I compounds are highly permeable and readily go into solution $(\mathrm{Dn}>1)$. In this case, the fraction absorbed (F) can be expressed as follows:

$$
\mathrm{F}=1-\exp (-2 \mathrm{An})
$$

For these agents, as "An" increases, the fraction of drug absorbed increases, with $90 \%$ absorption (highly permeable compounds) occurring when An $=1.15$. Referring back to the equation for $\mathrm{An}$, we see that $\mathrm{F}$ can be affected by a change in the compound's membrane permeability, the gut radius of the host, or the intestinal transit time. Based on these factors alone, it is evident that differences in GI physiology due to factors such as disease, age, or animal species can alter the value of An and, therefore, the fraction of drug absorbed.

For Class II drugs (high permeability, low solubility), $\mathrm{Dn}<1$. In these cases, the relationship between $\mathrm{D}_{0}$ and $\mathrm{Dn}$ is critical for determining the fraction of drug absorbed, and the rate of drug dissolution tends to be the rate-limiting step. Accordingly, anything that increases the rate and extent of in vivo dissolution will also increase the bioavailability of that compound.

\section{SOLUBILITY}

Aqueous solubility can be estimated by determining the ability of a drug to partition from lipid to aqueous environments. This partitioning behavior is often a function of solvent $\mathrm{pH}$ due to the latter's effects on drug ionization. In general, ionized drugs tend to exhibit far greater aqueous solubility than the un-ionized counterpart. Consequently, the rate of solute dissolution in aqueous media can be markedly affected by the $\mathrm{pH}$ of that solvent.

To examine the effect of $\mathrm{pH}$ on drug ionization, one can use a rearrangement of the Henderson-Hasselback equation: ${ }^{5}$

Weak acid: $\%$ un-ionized $=100 /(1+\operatorname{antilog}(\mathrm{pH}-\mathrm{pKa}))$.

Weak base: $\%$ un-ionized $=100 /(1+\operatorname{antilog}($ pKa-pH $))$.

Weakly basic drugs tend to have a slower dissolution rate at higher $\mathrm{pH}$ (when more drug exists in its unionized form), whereas weakly acidic drugs dissolve faster at higher $\mathrm{pH}$ (when more drug exists in its ionized form). Examples of the relationship between the percentage of drug in its un-ionized form as a function of drug pKa and $\mathrm{pH}$ are found in Figures 2 and 3. For this reason, by increasing the proportion of drug existing in its un-ionized state, meals that elevate gastric $\mathrm{pH}$ can decrease the dissolution of a weak base. For example, weak bases such as indinavir (with pKa of 3.7 and 5.9) are expected to precipitate when gastric $\mathrm{pH}$ is elevated during a meal, resulting in a significant reduction in AUC and $\mathrm{C}_{\max }$ values in fed versus fasted human subjects. ${ }^{6}$ Conversely, the same meal can increase the dissolution rate of a weak acid by increasing the proportion of drug existing in its ionized state, thereby making it more water soluble. ${ }^{7}$

By definition, solubility is the extent to which molecules from a solid are removed from its surface by a solvent. While solubility may be expressed in many ways, some generalizations can be made: ${ }^{8}$

Very soluble: Less than 1 part solvent needed to dissolve 1 part solute

Freely soluble: From 1 to 10 parts solvent needed to dissolve 1 part solute

Soluble: From 10 to 30 parts solvent needed to dissolve 1 part solute

Sparingly soluble: From 30 to 100 parts solvent needed to dissolve 1 part solute

Slightly soluble: From 100 to 1000 parts solvent needed to dissolve 1 part solute

Very slightly soluble: From 1000 to 10,000 parts solvent needed to dissolve 1 part solute

Practically insoluble: More than 10,000 parts solvent needed to dissolve 1 part solute

A compound's aqueous solubility, as measured by its propensity to distribute between octanol and water, is a function of its ability to form hydrogen bonds with the water molecule. Generally, aqueous solubility is directly proportional to the number of hydrogen bonds that can be formed with water. ${ }^{9}$ As discussed later, 


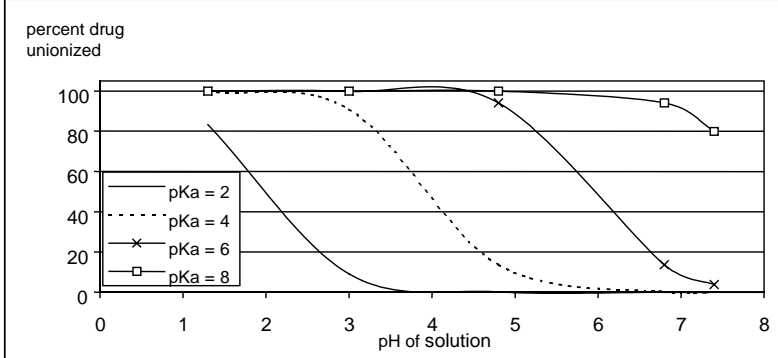

Figure 2. Relationship between percentage of drug un-ionized, and pH and pKa of weak acids.

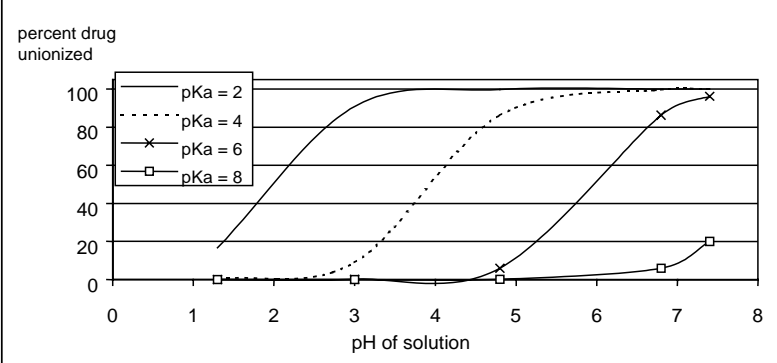

Figure 3. Relationship between percentage of drug un-ionized, and pH and $p K a$ of weak bases.

while very high aqueous solubility is beneficial for drug dissolution in aqueous media, these same compounds often exhibit low permeability due to their high polarity and poor lipophilicity.

Although lipid/water partitioning is often used to describe drug solubility, there is some evidence that solubility may better be described by the compound's dynamic energy properties. ${ }^{10}$ The solubility parameter of any compound can be described in terms of the energy required to fragment a molecule into its constituent atoms (its cohesive energy). When described in terms of the square root of its cohesive energy density (energy of vaporization per unit volume), the solubility parameter will lie on a scale from 10 (nonpolar) to 48 (water). For two materials to be miscible, their solubility parameters must be similar.

When comparing the percent absorbed versus $\log \mathrm{P}$ (octanol/water partition coefficient), the percent absorbed versus the solubility parameter, and the percent absorbed versus the number of hydrogen bond acceptors, it was noted that a high level of negative correla- tion was observed for the latter two relationships. Conversely, a large degree of scatter was observed in the relationship between permeability and log P. It was also noted that highly permeable compounds tend to have solubility parameter values almost identical to that of biological membranes (solubility parameter values of 20-26 $\mathrm{MPa}^{1 / 2}$ ). Accordingly, thermodynamic considerations rather than physicochemical interactions ${ }^{10}$ may serve as the best predictors of a compound's membrane permeability.

\section{IN VIVO DRUG ABSORPTION}

Efforts are currently under way to identify molecular quantitative structure-bioavailability relationships (QSBR) that predict drug bioavailability. ${ }^{11}$ Factors that negatively influence bioavailability include the number of hydrogen bond donors, the presence of heavy atoms, and the inclusion of fragments such as tetrazole, 4-animopyridine, and benzoquinone. Factors that tend to enhance drug bioavailability include the presence of hydrogen acceptors, low molecular weight, and the presence of fragments such as azide, salicylic acid, and amides.

To understand reasons for these structurebioavailability relationships, it is important to recognize the complex series of events that occur during the process of drug absorption. Molecular movement across lipid bilayers, such as those existing within biological membranes, is extremely complex due to the regional differences in membrane polarity, hydrophobicity, and density. Generally, the bilayer can be divided into four distinct regions. ${ }^{12}$ These include the following:

1. The first (outermost) region contains a high proportion of water molecules and may be the region responsible for interactions with other membranes and proteins.

2. The second region has the highest molecular density of all four regions (contains the polar headgroups), contains little or no water, and exerts the greatest barrier to solute diffusion (due to its density characteristics).

3. The third region contains the highest density of nonpolar tails. This region serves as the primary barrier to membrane penetration and is primarily responsible for the limitations in molecular size and shape associated with membrane transport.

4. The fourth region is the most hydrophobic region of the membrane, serving as a hydrophobic barrier in membrane transport.

Owing to this membrane structure, it is evident that drug permeability is not a simply two-step process of solubilization and diffusion but rather represents a 
spectrum of complex molecular events. Accordingly, intestinal permeability reflects a multifunctional interaction of factors such as molecular size (negatively correlated), lipophilicity (positively correlated), polar van der Walls surface area (negatively correlated), and the molecular flexibility (intramolecular hydrogen bond formation). ${ }^{13}$

In addition to cellular membrane barriers to drug diffusion, significant impedance is also effected by the components of the gastric and intestinal mucous layer. ${ }^{14}$ In examining the relative contribution of these various components, it was noted that lipid constituents such as phosphatidyl choline, cholesterol, and linoleic acid significantly retard the diffusion of small lipophilic molecules such as propranolol and hydrocortisone. Conversely, small hydrophilic molecules such as mannitol appear to freely diffuse through this lipoid barrier. Mucous gel-forming components, such as mucin and DNA, exert far less negative effects on the diffusion of lipophilic molecules. However, they may serve to block the diffusion of peptides and proteins.

Molecular flexibility and the corresponding ability to undergo conformation changes can significantly affect the polar surface area of a molecule. The polar surface area and nonpolar surface area are powerful predictors of intestinal permeability, being respectively inversely and directly related to membrane permeability. ${ }^{15}$ However, any particular set of descriptors may not adequately predict membrane permeability across nonhomologous compounds. ${ }^{9}$ Another important variable is the strength of the hydrogen bonds formed between the molecules of water and solute. ${ }^{15}$ It is generally assumed that these bonds must be broken (desolvation) before the solute can traverse the biological membrane. Which of these factors play the dominant role in determining drug permeability may vary across homologous drug series.

Despite these complexities, certain generalizations can be made with regard to drug absorption processes. For example, the vast majority of orally administered drugs are absorbed via passive transcellular transport. ${ }^{15}$ This necessitates that the drug traverse through a highly lipophilic membrane. Accordingly, diffusion processes are governed by Fick's laws of diffusion and therefore influenced by the compound's lipophilicity. This ability to diffuse through lipids has been found to be highly correlated with the ability of a drug to partition between water and an organic solvent such as octanol. In fact, when expressed as $\log \mathrm{P}_{0}$ (based on partitioning between n-octanol and water), the optimal partition coefficient for a drug generally falls within the range of 2 to $7 .{ }^{5}$ Nevertheless, exceptions do occur, and while transcellular transport generally occurs when the compound is un-ionized, recently, several ionized molecules have been shown to be absorbed via transcellular processes. ${ }^{16,17}$ This finding reinforces earlier statements regarding the degree of scatter associated with the relationship between $\log \mathrm{P}$ and drug absorption.

In addition to passive mechanisms, active transport is important to the absorption of several compounds. Both active and passive transport mechanisms may occur simultaneously for the same molecule. Which of these mechanisms has the dominant role tends to be compound specific and may not be well predicted by in vitro systems. ${ }^{15}$ Nevertheless, it must be remembered that even active transport mechanisms require that the drug penetrate the intestinal cells via the transcellular route.

The rate of passive diffusion of any molecule, whether it be absorbed via transport between mucosal cells or through the mucosal membrane, can be described by the following equation: ${ }^{18}$

$$
\begin{aligned}
\frac{d M}{d t}=A_{\mathrm{m}} & \bullet \frac{D_{m}}{\lambda} \bullet C_{\text {membrane }}+\frac{J_{\text {max }}}{K_{m}+C_{\text {lumen }}}+A_{p} \bullet \frac{D_{a q}}{\lambda_{a q}} \\
& \bullet C_{\text {lumen }}+J_{\text {fluid }} \bullet C_{\text {lumen }} \bullet(1-\alpha),
\end{aligned}
$$

where

$d M / d t \quad=$ the effective rate of passive drug absorption (concentration/time).

$D_{a q} \quad=$ the diffusion coefficient of the compound in water.

$\lambda_{a q}=$ the aqueous diffusion distance.

$J_{\text {fluid }} \quad=$ the fluid flow between epithelial cells

$\alpha=$ the ratio of the water flow relative to the solute flux, both under the influence of the existing pressure gradient, and is dependent on molecular size, volume, charge, and hydration number. It may also be influenced by the dynamic width of the tight junction.

$K=$ the partition coefficient describing the relative tendency of the substance to dissolve in the membrane phase $\left(C_{\text {membrane }}\right)$ as compared to the surrounding aqueous phase $\left(C_{\text {lumen }}\right)$.

$D_{m} \quad=$ the diffusion coefficient of the compound within the membrane, which is dependent on factors such as drug lipophilicity, hydrogen bonding capacity, polar surface area of the molecular, molecular volume, and shape.

$J_{\max }=$ the maximal transport capacity of the carrier-mediated process.

$K_{m} \quad=$ the substrate specificity of the membrane transporter (the Michaelis constant). 
$\lambda=\quad=$ the thickness of the rate-limiting diffusion barrier.

$A_{m}$ and $A_{p}=$ the available surface areas for transcellular and paracellular transport, respectively.

Thus, for passive diffusion, whether a drug is absorbed via paracellular or transcellular mechanisms is determined by both physicochemical and physiological factors.

Paracellular diffusion involves both diffusion and a convective volume flow through water-filled intercellular channels whose diameter is approximately 3 to $10 \AA$ in humans. ${ }^{18}$ Accordingly, the size and number of paracellular spaces influence the intestinal absorption of most hydrophilic compounds. This, in turn, is affected by the mucosal surface area and by cellular density. ${ }^{19}$ Therefore, it is not surprising that the bioavailability of small hydrophilic compounds tends to be greater in species such as dogs, in which both pore diameter and surface area tend to exceed that in humans. ${ }^{20}$ In humans, the small intestinal surface area for paracellular absorption is approximately $0.01 \%$ of the total membrane surface area. For this reason, unless the molecule is extremely small (e.g., < $200 \mathrm{Da}$ ), paracellular transport will have a minor role in drug absorption. ${ }^{15}$

With permeability-limited absorption, we can expect that although the fraction of dose absorbed remains unchanged, the absolute amount of drug absorbed will increase as dose increases (assuming linear kinetics). Conversely, for solubility-limited compounds, increasing the dose will have no effect on the absolute amount of drug absorbed. Consequently, in these cases, the fraction of dose absorbed will decrease as dose is increased. ${ }^{21}$ Moreover, permeability is not necessarily constant throughout the GI tract. While for some compounds, drug absorption appears to be site independent, ${ }^{22}$ for others, it is site dependent. ${ }^{23}$ When drug absorption is site dependent, the availability of dissolved drug at the absorption site can be the rate-limiting factor in product bioavailability.

\section{PRODUCT DISSOLUTION}

Drug absorption depends on delivery of the drug particles to its site of absorption. The Noynes-Whitney equation describes the variables that can affect drug dissolution: ${ }^{24,25}$

$$
\frac{d m}{d t}=\frac{D \bullet S}{V \bullet h}\left(C_{s}-C_{t}\right)
$$

where $d m / d t$ is the dissolution rate, expressed as the change in the amount of drug dissolved $(\mathrm{m})$ per unit time $(t) ; D$ is the diffusion coefficient; $S$ is the surface area; $h$ is the thickness of the diffusion film adjacent to the dissolving surface; $C_{s}$ is the saturation solubility of the drug molecule; $C_{t}$ is the concentration of the dissolved solute; and $V$ is the volume of the dissolution medium.

Upon integration, this equation can be expressed as follows: ${ }^{25}$

$$
\mathrm{m}=\frac{C_{s}}{V}(1-\exp (-K t))
$$

and

$$
K=S \bullet D / h
$$

The viscosity of the GI contents, ${ }^{23,26}$ as described by the following equation, can affect $D$, the diffusion coefficient:

$$
D=\left(K_{\mathrm{b}} T\right) /\left(6 \pi R_{0} \eta\right),
$$

where $D$ is the diffusivity of a compound, $\mathrm{K}_{\mathrm{b}}$ is the Bolzmann constant, $T$ is the temperature, $R_{0}$ is the solute radius, and $\eta$ is the viscosity of the diffusion medium.

As seen in the latter equation, increasing the surface area of a particle (S) can enhance its dissolution rate. $S$ can be increased by micronization, a process sometimes applied to poorly water-soluble compounds. ${ }^{24}$ Also to be considered are particle size and density, which both inversely affect the dissolution rate. ${ }^{27}$ Particle shape is also important in determining the dissolution behavior of a drug, and for many crystalline forms (particularly shapes of needles and platelets), shape and consequently dissolution behavior may change markedly as the particle dissolves. ${ }^{28,29}$

Particle properties can also affect the rate of GI transit, the latter being highly dependent on such properties as size, shape, and density. For example, in swine, about $30 \%$ to $40 \%$ of ingested food materials pass into the duodenum within 15 minutes in an adult pig. However, large particles (10 $\mathrm{mm}$ in diameter) are retained within the stomach of swine for several days, with residence time increasing with particle density and length. ${ }^{30}$

A problem with the Noynes-Whitney equation is that there is an inherent assumption that $S$ remains constant over time. Unfortunately, this assumption is incorrect, and the $\mathrm{S}$ of powders and immediate-release preparations tends to decrease as dissolution pro- 
ceeds. ${ }^{25}$ In vivo, many of these parameters are also influenced by the conditions of the GI tract, which will vary over time ${ }^{31}$ For this reason, these equations, while providing insights into the parameters that can affect drug dissolution, should not be blindly applied to predict in vivo dissolution rate.

It should be noted that because the Noynes-Whitney equations are unable to adequately model either S-shaped data or data with a steep initial slope, the more general Weibull distribution has been used to describe dissolution profiles. ${ }^{25}$ The Weibull distribution can be described as follows:

$$
M=1-\exp \left(-\alpha t^{\beta}\right),
$$

where $M$ is the accumulated fraction of material in solution at time $t, \alpha$ is a scale parameter, and $\beta$ is a shape parameter, where $\beta=1$ indicates an exponential relationship, $\beta>1$ indicates an S-shaped relationship, and $\beta<1$ indicates an exponential relationship with a steep slope.

The rate of product dissolution may or may not influence the resulting plasma concentration-time profile. For example, Class I compounds (highly soluble, highly permeable) may exhibit marked difference in the in vitro dissolution profiles without any resulting differences detected in product bioavailability. ${ }^{32-34}$ In these instances, gastric emptying is slower than product dissolution. Accordingly, it is the rate of gastric emptying rather than product performance that is the rate-limiting step in determining the bioavailability characteristics of that formulation. Similarly, highly soluble, poorly permeable compounds (Class III) dissolve rapidly. However, in these cases, it is not the rate of drug dissolution that is usually rate limiting but rather the rate of permeation across biological membranes. Therefore, we can again assume that so long as dissolution is faster than the rate of gastric emptying, product dissolution will not determine product bioavailability. In the case of Class III compounds, so long as absorption occurs via linear processes, the absolute amount of drug absorbed may be increased by increasing the dose. ${ }^{21}$

On the other hand, for high-permeability, lowsolubility compounds (Class II), the rate and extent of product dissolution will have a significant role in defining the resulting blood concentration-time profile. ${ }^{27}$ This may be attributable to problems associated with either particle size (termed dissolution-limited absorption) or drug solubility (termed solubility-limited $a b$ sorption). In the case of solubility-limited absorption, particle size exerts minimal effect on the fraction of drug absorbed. In this situation, fraction of drug absorbed can only be improved by enhancing drug solubility (e.g., via the inclusion of surfactants in the product formulation). Conversely, particle size exerts its greatest effect when solubility is not a problem. In these cases, a significant improvement in the fraction of drug absorbed can be achieved by increasing surface area (i.e., decreasing particle size).

The FDA's Center for Drug Evaluation and Research (CDER) has written a guidance that provides for the waiver of in vivo bioequivalence study requirements for high-solubility/high-permeability drug products based on in vitro dissolution data. The scientific and regulatory considerations that must be applied to these procedures are described in the CDER guidance titled Waiver of In Vivo Bioavailability and Bioequivalence Studies for Immediate-Release Solid Oral Dosage Forms Based on a Biopharmaceutics Classification System (August 2000). For Class I compounds, the bioequivalence of generic or revised versions of marketed drug products can be confirmed if the sponsor can demonstrate that gastric emptying is the rate-limiting step in product absorption.

To be granted a waiver of in vivo bioequivalence study requirements, the CDER recommends that in vitro dissolution tests be conducted under the following conditions:

- The test apparatus is USP Apparatus I at $100 \mathrm{rpm}$ or Apparatus II at $50 \mathrm{rpm}$. Testing is conducted in $900 \mathrm{ml}$ of each of the following dissolution media: (1) $0.1 \mathrm{~N}$ $\mathrm{HCl}$ or Simulated Gastric Fluid USP without enzymes, (2) a pH 4.5 buffer, and (3) a pH 6.8 buffer or Simulated Intestinal Fluid USP without enzymes.

- For each formulation, a minimum of 12 dosage units is evaluated to support a biowaiver request. Samples should be collected at time intervals adequate for characterizing the dissolution profile of the drug product. When comparing the test and reference formulations, the respective dissolution profiles should be compared using the similarity factor $\left(f_{2}\right)$, where

$$
\mathrm{f}_{2}=50 \bullet \log \left\{\left[1+(1 / n) \sum_{\mathrm{t}=1}^{n}\left(\mathrm{R}_{\mathrm{t}}-\mathrm{T}_{\mathrm{t}}\right)^{2}\right]^{-0.5} \bullet 100\right\},
$$

where $R_{t}$ is the percent dissolved of the reference product, $\mathrm{T}_{\mathrm{t}}$ is the percent dissolved of the test product, and $n$ is the number of units tested.

- Two dissolution profiles are considered similar when the $f_{2}$ value is $\geq 50$. To allow the use of mean data, the 
coefficient of variation should not exceed $20 \%$ at the earlier time points (e.g., 10 minutes) or $10 \%$ at all other time points. If, under all dissolution conditions, both the test and reference products dissolve at a rate of $85 \%$ or more within 30 minutes, profile comparisons are not necessary.

The BCS and in vivo/in vitro correlation concepts (IVIVC) have also been incorporated into several CDER guidances pertaining to scale-up and postapproval changes for immediate-release and sustained-release dosage forms. As with products that contain Class I compounds, in vivo bioequivalence determinations for certain types of postapproval changes may be generated on the basis of in vitro dissolution data. For more information in this regard, refer to the CDER Web site. ${ }^{35}$

The absorption of controlled-release dosage forms is, by definition, dissolution-rate limited. Since drug permeability characteristics must be sufficiently high to ensure the presence of sink conditions within the GI tract, the appropriate candidates for these products are Class I or II compounds. ${ }^{36}$ Moreover, to develop an IVIVC for these products, test procedures must account for the changing environments to which the oral dosage form will be exposed as it traverses down the GI tract. These include the following:

- the impact of changes in fluid volume, surfactants, and motility patterns on product dissolution and drug solubility;

- regional differences in intestinal permeability and surface area;

- regional differences in intestinal metabolism and secretions.

\section{PRESYSTEMIC DRUG METABOLISM}

Oral bioavailability (F) can be described as follows: ${ }^{37}$

$$
\mathrm{F}=f_{\text {abs }} \bullet\left(1-f_{\mathrm{g}}\right) \bullet\left(1-f_{\mathrm{h}}\right),
$$

where $f_{\text {abs }}$ is the fraction of the dose absorbed from the GI lumen, $f_{\mathrm{g}}$ is the fraction of drug metabolized by the gut wall, and $f_{\mathrm{h}}$ is the fraction of drug metabolized by the liver.

An excellent example of the importance of first-pass metabolism is exemplified by the impact that interspecies differences in drug metabolism have on product bioavailability. For example, the observed interspecies differences in the oral bioavailability of indinavir $(72 \%$ in dogs, $24 \%$ in rats, and $19 \%$ in monkeys) is attributable to species differences in hepatic first-pass extraction (approximately 68\% in rats, 65\% in monkeys, and $17 \%$ in dogs). ${ }^{38}$ In human subjects, the oral bioavailability of indinavir is approximately $60 \% .^{39}$

Lin et a ${ }^{37,38}$ provide an excellent discussion of factors that can affect the clearance and therefore overall bioavailability of compounds. He describes hepatic clearance $\left(\mathrm{CL}_{\mathrm{H}}\right)$ as follows:

$$
\mathrm{CL}_{\mathrm{H}}=\mathrm{Q}_{\mathrm{h}} \bullet \mathrm{E} \text {, and } \mathrm{E}=\left[\left(f_{\mathrm{b}} \bullet \mathrm{CL}_{\text {int }}\right) /\left(\mathrm{Q}_{\mathrm{h}}+f_{\mathrm{b}} \bullet \mathrm{CL}_{\text {int }}\right)\right] \text {, }
$$

where $\mathrm{Q}_{\mathrm{h}}$ is hepatic blood flow, $\mathrm{E}$ is the hepatic enzyme extraction ratio, $f_{\mathrm{b}}$ is the unbound fraction of drug in the blood, and $\mathrm{CL}_{\text {int }}$ is the intrinsic clearance (a measure of $\mathrm{V}_{\max } / \mathrm{K}_{\mathrm{M}}$ ).

When $\mathrm{Q}_{\mathrm{h}} \gg>f_{\mathrm{b}} \bullet \mathrm{CL}_{\text {int }}$, then $\mathrm{CL}_{\mathrm{H}}=\mathrm{Q}_{\mathrm{h}} \bullet\left[\left(f_{\mathrm{b}} \bullet \mathrm{CL}_{\text {int }}\right) /\left(\mathrm{Q}_{\mathrm{h}}\right.\right.$ $\left.\left.+f_{\mathrm{b}} \bullet \mathrm{CL}_{\text {int }}\right]\right]$, which tends toward

$$
\begin{aligned}
f_{\mathrm{b}} & \bullet \mathrm{CL}_{\text {int }} \bullet \mathrm{Q}_{\mathrm{h}} / \mathrm{Q}_{\mathrm{h}} \\
= & f_{\mathrm{b}} \bullet \mathrm{CL}_{\text {int }} \bullet 1 \\
= & f_{\mathrm{b}} \bullet \mathrm{Cl}_{\text {int }} .
\end{aligned}
$$

Conversely, when $\mathrm{Q}_{\mathrm{h}}<<f_{\mathrm{b}} \bullet \mathrm{CL}_{\text {int }}$, then $\mathrm{CL}_{\mathrm{H}} \sim \mathrm{Q}_{\mathrm{h}}$.

For high E compounds, $\mathrm{CL}_{\mathrm{H}}$ is said to be blood flow limited (i.e., $\mathrm{Q}_{\mathrm{h}}<<f_{\mathrm{b}} \bullet \mathrm{CL}_{\text {int }}$ ). In other words, $\mathrm{CL}_{\mathrm{H}}$ will be affected by anything that can alter $\mathrm{Q}_{\mathrm{h}}$ (or $\mathrm{Q}_{\mathrm{h} \text {-splannnic }}$ for oral first-pass effects). In these cases, factors altering intrinsic clearance $\left(\mathrm{CL}_{\text {int }}\right)$, such as drug-drug interactions, should have minimal impact on $\mathrm{CL}_{\mathrm{H}}$. Alternatively, for low $\mathrm{E}$ drugs, $\mathrm{CL}_{\mathrm{H}} \sim f_{\mathrm{b}} \bullet \mathrm{CL}_{\text {int }}$. In this situation, any factor that alters $f_{\mathrm{b}}, \mathrm{V}_{\max }$, or $\mathrm{K}_{\mathrm{M}}$ can markedly affect $\mathrm{CL}_{\mathrm{H}}$.

An example of these interrelationships is seen with the interaction between indinavir (oral or intravenous administration) and ketaconazole (oral administration). ${ }^{38} \mathrm{In}$ rats, indinavir is a high-clearance drug whose $\mathrm{CL}_{\mathrm{int}}\left(80-90 \mathrm{ml} / \mathrm{min} / \mathrm{kg}\right.$ ) exceeds the $\mathrm{Q}_{\mathrm{h}}(60-70$ $\mathrm{ml} / \mathrm{min} / \mathrm{kg}$ ). Ketoconazole is a low-clearance drug. Ketoconazole competitively inhibits the metabolism of indinavir, and indinavir inhibits the metabolism of ketaconazole. As expected, since $\mathrm{CL}_{\text {int }}$ exceeds systemic blood flow to the liver, ketoconazole has practically no effect on the AUC of intravenously administered indinavir. However, when indinavir is administered orally, drug coadministration results in an increase in indinavir bioavailability from about $20 \%$ in the control group to $89 \%$ in the ketoconazoletreated group. Clearly, the difference is attributable to first-pass metabolism. However, the question is whether differences between intravenous versus oral results were attributable to the effect of ketoconazole on the liver, small intestine, or both.

When indinavir is orally administered, the entire dose passes through the liver. Accordingly, we expect greater hepatic drug loss when the drug is administered 
orally versus parenterally. Alternatively, we must also consider the possibility that the increase in indinavir oral bioavailability was attributable to the effect of ketaconazole on intestinal first-pass drug metabolism. ${ }^{40}$ That both mechanisms were likely to have been operative was strongly suggested by the results obtained when indinavir (intravenous vs. oral doses) was coadministered with dexamethasone. ${ }^{41}$ In the latter study, dexamethasone induced the activity of both CYP $3 \mathrm{~A}$ and P-gp, and the authors demonstrated that while both liver and gut metabolism were potentiated, dexamethasone had a substantially greater impact on the hepatic metabolism. At least in part, these studies underscore the importance of considering the route of administration when considering the impact of potential drug-drug interactions.

Lin et $\mathrm{al}^{37}$ emphasize that the greater changes in bioavailability seen after oral versus parenteral administration should not automatically be attributed to a greater degree of enzyme induction/inhibition in the small intestine. This point is underscored by the following two equations:

$$
\mathrm{AUC}_{\mathrm{IV}}=\frac{\text { Dose }}{f_{\mathrm{B}}\left(\mathrm{F}_{\mathrm{H}} \bullet \mathrm{CL}_{\mathrm{int}, \mathrm{h}}+\mathrm{F}_{\mathrm{H}} \bullet \mathrm{F}_{\mathrm{G}} \bullet \mathrm{CL}_{\mathrm{int}, \mathrm{g}}\right)}
$$

and

$$
\mathrm{AUC}_{\mathrm{PO}}=\frac{f_{\mathrm{abs}} \text { Dose }}{f_{\mathrm{B}}\left(\frac{\mathrm{CL}_{\mathrm{int}, \mathrm{h}}}{\mathrm{F}_{\mathrm{G}}}+\mathrm{CL}_{\mathrm{int,g}}\right)},
$$

where $f_{\text {abs }}$ is the fraction of drug absorbed; $\mathrm{F}_{\mathrm{H}}$ and $\mathrm{F}_{\mathrm{G}}$ are the fraction of drug not metabolized by the liver or gut, respectively; $f_{\mathrm{B}}$ is the unbound fraction of drug in plasma; and $\mathrm{CL}_{\mathrm{int}, \mathrm{h}}$ and $\mathrm{CL}_{\mathrm{int}, \mathrm{g}}$ are the intrinsic clearance of the liver and gut, respectively.

Based on these equations, it can be seen that increases in $\mathrm{CL}_{\text {int, } \mathrm{h}}$ and $\mathrm{CL}_{\text {int, } \mathrm{g}}$ will be offset by the multipliers $F_{H}$ and $F_{G}$ when the drug is administered by a nonoral route (e.g., intravenous injection). In other words, as hepatic or intestinal clearance increases (e.g., due to the coadministration of an enzyme inhibitor), the fraction of drug not metabolized will increase. Therefore, the values $\mathrm{F}_{\mathrm{H}} \bullet \mathrm{CL}_{\text {int, } \mathrm{h}}$ and $\mathrm{F}_{\mathrm{H}} \bullet \mathrm{F}_{\mathrm{G}} \bullet \mathrm{CL}_{\text {int, }}$ are diminished, minimizing the resulting changes in $\mathrm{AUC}_{\mathrm{IV}}$. Conversely, after oral administration, an increase in hepatic clearance will be amplified by dividing $\mathrm{CL}_{\mathrm{int}, \mathrm{h}}$ by $\mathrm{F}_{\mathrm{G}}$. In addition, intestinal clearance is not counteracted by the concomitant changes in the fraction of unmetabolized drug. For this reason, changes in $\mathrm{AUC}_{\mathrm{PO}}$ will generally exceed changes in $\mathrm{AUC}_{\mathrm{IV}}$ associ- ated with the coadministration of an enzyme inducer or inhibitor. Using simulations, Lin et $\mathrm{al}^{37}$ demonstrated that both enzyme induction and inhibition will have a less profound effect on $\mathrm{AUC}_{\mathrm{IV}}$ as compared with $\mathrm{AUC}_{\mathrm{PO}}$, regardless of whether the compound in question is a high- or low-clearance drug.

The latter study points to the importance of considering the small intestine as a potential site of drug metabolism. Substantial drug loss can occur via intestinal efflux mechanisms, gut wall metabolism (both Phase I and Phase II), and degradation within the gut lumen. ${ }^{37,42,43}$ The cytochrome $\mathrm{P} 450$ system constitutes the principle enzymes involved in the biotransformation of drugs and other substances. ${ }^{37}$ Approximately $70 \%$ of the human liver P450 is accounted for by CYP1A2, 2A6, 2B6, 2C, 2D6, 2E1, and 3A isoforms. ${ }^{37}$ While the total amount of P-450 in the human intestine is much less than that in the liver $(20 \mathrm{pmol} / \mathrm{mg}$ microsomal protein vs. $300 \mathrm{pmol} / \mathrm{mg}$ microsomal protein, respectively), the intestinal enzymes are strategically situated to maximize their exposure to intestinal contents. P450 concentrations tend to be greatest in the villus tips of the upper and middle third of the intestine. ${ }^{44}$

Examples of drugs subject to gut wall metabolism include midazolam, ${ }^{45}$ amoxicillin, ${ }^{46}$ and cyclosporin. ${ }^{47}$ Interestingly, several major Phase I metabolizing enzymes co-reside at the villus tips, providing a highly efficient mechanism for drug degradation. ${ }^{48}$ Of particular importance is the synergistic function of P-gp and cytochrome P450 3A4, which together are responsible for the active extrusion and subsequent metabolism of a wide variety of compounds. ${ }^{49}$ The latter is discussed in more detail in the section of this review that focuses on membrane transporter systems.

Compounds may also be extensively metabolized in the gut lumen by digestive enzymes or by activity of the gut microflora. An excellent example of the potential negative impact of microbial metabolism is the species-by-route differences in blood concentrations achieved when chloramphenicol is administered to goats, pigs, dogs, cats, and horses. Despite high levels achieved in the goat after intramuscular administration, the oral bioavailability of this compound was minimal due to microbial degradation in the gut. Similar problems did not occur with the other animal species. ${ }^{50}$ Conversely, the presence of gut microflora may enhance drug bioavailability by promoting biliary recycling of compounds such as ouabain, digoxin, and steroid hormones (e.g., Aldercreutz et $\mathrm{al}^{51}$ ). In these cases, the bacteria remove the polar moiety from the derivatized conjugates, rendering them available for intestinal absorption. ${ }^{42}$ 
When evaluating the impact of drug metabolism on product bioavailability, patient phenotype should be considered (see Lu et al, ${ }^{52}$ Mancinelli et $\mathrm{al}^{53}$ ). Of equal importance may be the potential impact of certain nutrients, hormones, and inflammatory processes on the activity of these enzymes, ${ }^{54}$ as well as that of concomitant medications. In this regard, Dr. David A. Flockhart, $\mathrm{MD}, \mathrm{PhD}$, in the Division of Clinical Pharmacology at Georgetown University, has developed a free database summarizing substances that act as substrates, inducers, and inhibitors of the P450 enzymes. The database includes Medline links to pertinent references for each of these substrates. ${ }^{55}$

\section{FORMULATION EFFECTS}

By understanding the relationship between Dn, $D_{0}$, and An, we can assess whether a product's bioavailability will be solubility, permeability, or dissolution rate limited. Amidon et $\mathrm{al}^{2}$ list several factors that can affect in vivo drug absorption characteristics. These include the following:

- $\mathrm{pH}$ dependent solubility of the active ingredient,

- drugs that form insoluble complexes with the GI contents,

- instability in the GI tract,

- physicochemical interaction of drug particles. For example, to enhance the rate of drug dissolution of Class II compounds, the drug particles may be micronized. While this generally increases particle surface area (and therefore drug dissolution), micronized particles may also have a greater tendency to form aggregates, thereby decreasing drug dissolution.

Surface area (S from the Noynes-Whitney equation) can be enhanced via the use of wetting agents that lower the surface tension of the dissolution medium. Examples include dispersing agents such as polyethylene glycol and polyvinyl pyrrolidone or complexing agents such as cyclodextrins. ${ }^{24,56}$ However, surfaceactive agents that increase drug water solubility are not generally used in product formulations because the amount of surfactant needed to enhance in vivo product dissolution may compromise product safety. ${ }^{24}$ In the case of some very poorly water-soluble drugs, the inclusion of insoluble carriers may provide a mechanism for maintaining the concentration gradient $\left(\mathrm{C}_{\mathrm{s}}-\mathrm{C}_{\mathrm{t}}\right)$ at its maximum. ${ }^{24}$

For drugs that exhibit high solubility, low intestinal permeability, it is intestinal permeability that is the rate-limiting step in drug absorption. ${ }^{57}$ In the BCS system, these are considered Class III compounds. A con- sequence of permeability-limited absorption is that the rate of dissolution is generally far less important than the rate of GI transit. Consequently, formulations of Class III compounds may exhibit markedly different rates of dissolution without affecting any difference in the blood concentration-time profile. ${ }^{58}$ However, Class III compounds may be extremely sensitive to the potential excipient effects on GI transit time and permeability.

Some excipients are known to exert direct physiological affects. For example, owing to its osmotic activity, certain sugar alcohols (e.g., mannitol) decrease GI transit time, resulting in more rapid product transit through the intestine. ${ }^{59}$ Another compound known to alter GI transit time is sodium acid pyrophosphate. ${ }^{60}$ Consequently, if the drug is slow to dissolve, the inclusion of these agents could significantly reduce product bioavailability. Obviously, these excipient effects would go undetected by tradition in vitro dissolution methods. Other examples of potential in vivo excipient effects that could go undetected during in vitro dissolution testing include the affect of surfactants on membrane permeability (e.g., Del Estal et al ${ }^{61}$ ) and the inhibition of efflux pumps. ${ }^{62,63}$ Accordingly, one cannot necessarily view excipients as benign inactive ingredients but rather as potentially powerful components that can affect all aspects of drug bioavailability.

For excellent reviews regarding the use of excipients in product formulation and their potential effects on drug bioavailability, refer to Monkhouse and Lach, ${ }^{64}$ Kalinkova, ${ }^{65}$ and Pifferi et al. ${ }^{66}$

\section{VARIABLES THAT CAN AFFECT PRODUCT BIOAVAILABILITY}

\section{Food Effects}

The effect of food on drug oral bioavailability is extremely complex, and the underlying reason for food effects appears to differ with different agents. For example, in some cases, it appears that caloric content is an important variable contributing to the magnitude of the food effect. In other cases, caloric content appears to have minimal influence on drug bioavailability. ${ }^{23}$. When drug absorption is facilitated by surfactants, food may enhance product bioavailability. In other cases, it can have negative effects on both the rate and extent of absorption as the drug binds to food constituents. ${ }^{23}$

Depending on the physicochemical properties of the compound, food-induced changes in gastric emptying, along with an increase in gastric $\mathrm{pH}$, may increase, decrease, or have no effect on drug availability. ${ }^{7}$ For exam- 
ple, certain antibacterial products are acid labile, and increased drug degradation due to prolonged gastric residence may result if the dose is coadministered with food. In other cases, meal-induced alterations in gastric $\mathrm{pH}$ may affect drug absorption. Poorly soluble weak bases may precipitate in the presence of food-induced gastric $\mathrm{pH}$ elevations. Conversely, the degree of ionization may increase when a weak acid is exposed to a meal-induced increase in gastric $\mathrm{pH}$, thereby enhancing its solubility and bioavailability. ${ }^{7}$ Alternatively, some weak bases exhibit decreased bioavailability in the presence of a high-fat meal due to the formulation of a drug-bile acid complex. ${ }^{67}$

These factors are discussed below, with particular consideration given to drug solubility and permeability characteristics.

\section{Effect of Meals on GI Transit Time}

The rate at which the fluid empties is highly dependent on the phase of the electrical cycle observed in mammalian GI systems. Cyclic motor activity has been observed under fasting conditions in both humans and dogs. ${ }^{68-71}$ These interdigestive migrating myoelectric complexes (IMMC) occur on the order of once every 90 to 120 minutes and are characterized by three phases:

- Phase I: the quiescent period

- Phase II: intermittent and irregular contractions

- Phase III: brief period of intense contractions. This phase is responsible for moving both liquid and solid materials down the GI tract.

By increasing fluid volume, the gastric emptying rate increases ${ }^{72}$ regardless of the phase of IMMC phases. ${ }^{68}$ The effect that smaller volumes exert on the rate of gastric emptying is more greatly influenced by the phase of stomach activity than is seen with larger fluid volumes. ${ }^{68}$ This relationship can affect the variability observed in the bioavailability of a dosage form. Accordingly, fluid volume may be particularly important for drug classes where dissolution is rapid and the availability of dissolved drug to the intestinal tract is limited by the rate of gastric emptying (BCS Class I and III compounds).

\section{The Effect of Nutrients on Drug Uptake: Uncertainties Surrounding the Importance of Solvent Drag}

Transmucosal fluid flow appears to increase the membrane permeability of both hydrophilic and lipophilic compounds. ${ }^{18}$ This phenomenon is known as solvent drag. For certain small hydrophilic molecules, it is likely that a meal-induced increase in water absorption will effect an increase in intestinal permeability. These effects appear to be attributable to the impact of nutrients on solvent drag and to water-transport changes in drug access to paracellular pathways. ${ }^{52}$ However, in other situations, the physiological relevance of solvent drag has been questioned..$^{18}$

Small hydrophilic molecules are generally absorbed within 4 hours after dosing in man, after which absorption ceases, most probably due to drug entry into the large bowel..$^{18}$ Based on studies conducted in vitro, in situ, and in vivo (perfusion models), it is observed that the absorption of nutrients significantly increases the membrane permeability of hydrophilic molecules (molecular weight [MW] 60-5500). While solvent drag has been repeatedly demonstrated in model systems, its applicability to human drug absorption and its utility as a mechanism for enhancing the bioavailability of low-permeability compounds in humans has been questioned. ${ }^{18}$ Moreover, while solvent drag may facilitate the absorption of small hydrophilic molecules, enhanced fluid absorption may impede the absorption of Class II molecules. In this case, drug solubility is a rate-limiting variable. Therefore, an increase in water absorption may decrease GI fluid volume and consequently lead to drug precipitation within the gut lumen.

More recently, using two in vitro preparations, Caco-2 cell monolayers and rat ileal mucosa, it was concluded that the stimulation of epithelial water absorption is inadequate to enhance paracellular intestinal drug absorption. ${ }^{73}$ However, other work has suggested that the intestine is a heteroporous membrane consisting of several sizes of pores whose diameters are dependent on the specific villus region. ${ }^{74}$ It was proposed that the absorbing apical part of the villus contains small pores (radius $<6 \AA$ ), while those in the basal part of the villus are somewhat larger (10-14 $\AA$ ), and those in the crypts are larger still (50-60 $⿱$ ). In this rat study, active glucose transport was found to increase the absorption of mannitol $(\sim 3.5 \AA)$ while not affecting absorption of the larger molecules, suggesting that solvent drag may occur in a region-specific manner. It was noted, however, that the identical protocol did not produce comparable findings in the cat, ${ }^{75}$ which could indicate the possibility of species-specific differences in pore size distribution and the importance of solvent drag.

\section{Meal Effects on Drug Diffusivity}

The effect of meal viscosity on drug absorption will depend on whether or not there exists site-specific ab- 
sorption, particularly if absorption is limited to the upper portions of the small intestine. ${ }^{23,76}$ If the drug exhibits site-specific absorption, then meal-induced decrease in diffusivity $(D)$ may impede drug absorption as the drug moves past the absorption site. However, the effect of initial meal viscosity on $D$ tends to diminish as the meal moves down the small intestine, an effect attributed to digestion and the release of GI fluids. Therefore, if the drug is absorbed throughout the small intestine, then meal viscosity should have little effect on the extent of drug absorption.

When present, altered drug absorption associated with meal viscosity appears to be attributable primarily to altered fluid flow dynamics rather than to altered GI motility ${ }^{76,77}$ However, only modest changes in gastric emptying rate are observed when viscosity increases above 15,000 cp. Accordingly, viscosity-induced delays in gastric emptying are primarily seen when comparing changes that occur within the lower range of potential viscosity values. ${ }^{76}$ For this reason, viscosity effects on drug bioavailability are generally considered to be primarily a consequence of the effect of viscosity on $D .^{6}$ This relationship can be explained by the Noynes-Whitney equation, where the drug dissolution rate $(d m / d t)$ is directly proportional the diffusion coefficient $(D)$.

\section{The Effect of Nutrients on First-Pass Drug Metabolism}

Intestinal $\mathrm{P} 450$ s tend to respond more rapidly to inducers as compared to hepatic P450 enzymes. It has been postulated that this discrepancy is related to a greater availability of these inducer substances to the intestinal mucosa. Consistent with this postulation is the observation that while dietary restriction of iron causes a marked and rapid decrease in intestinal P450 concentrations and oxidative enzyme activities, these activities are restored within 24 hours when iron is administered via oral but not parenteral dosing. ${ }^{44}$

There are numerous examples of enzyme modulators in the foods we consume. ${ }^{44,78}$ These include the following:

- Charcoal-broiled and smoked foods: These polycyclic aromatic hydrocarbons are potent inducers of CYP1A1 and CYP1A2. Examples of drugs whose bioavailability may be decreased because of these effects include pheacetin and theophylline.

- Grapefruit juice: An undefined compound within grapefruit juice is recognized to inhibit both PGP (a multidrug resistance protein) and CCYP3A. As a result, there is enhanced bioavailability of compounds such as estradiol, felodipine, and cyclosporin.
- Cruciferous vegetables: These can induce several enzymes that include Phase II enzymes such as glutathione-s-transferase and quinone oxidoreductase and Phase I enzymes such as the CYP1A subfamily.

- Watercress: This is an inhibitor of CYP2E1.

- Red and black pepper: These contain capsacin, which inhibits CYP1a, CYP2B, and CYP2E1.

- Black pepper: This contains piperine, which inhibits CYP1A and glucuronidation.

- Sodium chloride: High levels may increase CYP3A activity.

For drugs exhibiting a large first-pass effect, concomitant intake with food may increase drug availability. A classical example of this is propranolol $;^{79}$ as a result of, in part, its saturable first-pass metabolism, a foodinduced increase in hepatic drug delivery can lead to reduced presystemic metabolism. Another critical variable is the volume of fluid taken with the dose, whereby increasing the volume of fluid intake from 25 $\mathrm{ml}$ to $250 \mathrm{ml}$ significantly increases the rate and extent of aspirin bioavailability. ${ }^{72,80}$ This relationship appears to be attributable to the decrease in first-pass metabolism associated with a fluid volume-induced decrease in GI transit time.

There appears to be little correlation between the expression of a particular metabolizing enzyme in the intestine versus that in the liver. This results in marked interindividual variability in the relative contributions of the intestine versus liver to first-pass drug loss, a point that needs to be considered by physicians when prescribing dose amount and use conditions to patients across a range of phenotypic populations. Moreover, as seen in studies previously referenced in this review, the oral administration of an inducer or inhibitor may have a greater impact on GI enzymes as compared with the more distal hepatic enzymes. ${ }^{78}$ Therefore, in terms of formulation considerations, this difference in relative activities may alter the impact, including enzyme modulators, in product formulations.

For further information in this regard, an extensive list of metabolic pathways and associated information can be obtained through the World Wide Web. ${ }^{81}$

\section{APPLYING BCS CONCEPTS TO PREDICT THE IMPACT OF PHYSIOLOGICAL STATE AND FOOD ON PRODUCT BIOAVAILABILITY}

There are numerous examples where an a priori knowledge of a compound's physicochemical properties and 
BCS classification can help predict its bioavailability under a given set of conditions. For example, weak bases with poor aqueous solubility (such as dipyridamole and ketaconazole) are often associated with absorption problems in achlorhydric individuals. ${ }^{82,83}$ Similarly, we would expect that the bioavailability of these compounds will be compromised in the presence of food.

GI transit time can also be altered by a number of factors, including age, food, drug excipients, disease, and even some over-the-counter medications. ${ }^{7}$ In this regard, the BCS can be used to predict those compounds whose bioavailability may be particularly sensitive to changes in GI transit. Insight in this regard can be obtained from the results of studies suggesting that animal species with rapid GI transit (e.g., dogs) may be more sensitive to changes in the in vivo dissolution rate as compared to species with a longer transit time such as swine. ${ }^{84}$ Thus, we can predict that Class II compounds (high permeability, low solubility) that tend to have dissolution rate-limited absorption may be particularly sensitive to factors that influence GI transit time. These factors alone may exaggerate differences in the in vivo bioavailability, rendering products inequivalent under certain sets of conditions (affecting switchability). Conversely, we would not expect to see marked changes in product-relative bioavailability for Class III compounds (low permeability, high solubility) in response to decreased GI transit time. In these cases, it is drug absorption, not dissolution, that is the rate-limiting step (i.e., switchability of two products will remain relatively unaffected). However, we are likely to see that a decrease in GI transit time will decrease drug bioavailability, thereby affecting product prescribability. Individuals from areas of poor hygiene and sanitation appear to have significantly lower absorptive capacities, a finding that appears to be correlated with changes in intestinal morphology connected with subclinical infections. ${ }^{85}$ Therefore, these individuals may potentially exhibit poor bioavailability of many Class III compounds.

The conditions of the GI tract, including the number of villi, microvilli, motility, probability of forward molecular movements, prandial state, and fluid volume, can greatly affect drug absorption. ${ }^{86}$ Given that these conditions change markedly across the length of the GI tract, the gut must be viewed as a complex heterogeneous system. Traditionally, drug absorption processes are modeled in accordance with the assumption of time-invariant processes (rate constants). While this may be correct for rapidly dissolving drugs (e.g., Class I and III compounds), it is unlikely to be the case for drugs that are absorbed throughout the GI tract or that dissolve throughout the length of the small intestine. In the latter situations, dissolution and uptake processes are subjected to highly variable conditions, and the use of well-stirred models is inappropriate. ${ }^{87}$

The assumption of time invariance is traditionally employed by pharmacokineticists. While time-invariant absorption may adequately describe Class I compounds (as well as some Class II and III compounds), it cannot adequately describe drugs with very low solubility and/or permeability. Therefore, the use of time-variant models may be more appropriate for describing the absorption of certain Class II, III, or IV compounds. ${ }^{84}$ It may also be useful to describe the effect of food on drug absorption, particularly since the impact of food on GI environment and viscosity decreases as the meal traverses the small intestine.

Fleisher et $\mathrm{al}^{7}$ provide an excellent review of the variables that can affect product bioavailability. In brief, some of the factors that can potentially affect oral drug bioavailability include the following:

1. Anything that can alter GI pH, including meals, drugs, age, and disease

2. Complexation and chelation between drug and metal ions (e.g., decrease in fluoroquinolone bioavailability due to complexation with metal ions)

3. Drug adsorption onto meal components such as pectins and fiber (e.g., decrease in penicillin $\mathrm{V}$ bioavailability due to binding to dietary fiber)

4. Acid instability (e.g., decrease in oral bioavailability of erythromycin), requiring products to be formulated either with enteric coatings or with an antacid to minimize drug instability (e.g., didanosine, an acid-labile reverse transcriptase inhibitor)

5. Enzymatic hydrolysis of orally administered peptides and proteins, necessitating novel formulation (e.g., prodrugs, or encapsulated formulations)

6. Meal-induced increase in viscosity in the duodenum (affects primarily those drugs absorbed in the upper small intestine), thereby impeding drug absorption

7. Altered gastric emptying time due to stomach volume, calories, osmolarity, viscosity, and temperature. Solid meals tend to empty more slowly than liquid meals, although high-calorie liquid meals can delay gastric emptying. Undissolved particles of a diameter less than 1 to $12 \mathrm{~mm}$ will tend to empty with the fluid.

8. Product excipients that directly affect GI transit time

9. Increase in splanchnic blood flow: This may increase the oral absorption of certain low first-pass effect drugs or those high first-pass effect compounds that are absorbed in the upper part of the small intestine and that exhibit saturable first-pass metabolism. Conversely, it may decrease the bioavailability of high first-pass effect compounds that do not exhibit satura- 
tion kinetics or that are absorbed throughout the small intestine.

10. Food effects: These effects are considered relative to a drug's pKa and its BCS classification:

- Class I compounds are, by definition, highly soluble across a wide range of $\mathrm{pH}$ values. Therefore, food is not expected to alter the extent of product absorption. However, the delay in gastric emptying may affect peak drug concentrations or the time to peak drug concentrations.

- Class II compounds exhibit low solubility and high permeability. Accordingly, anything that can enhance its in vivo dissolution will also increase product absorption. Due to the low solubility of Class II compounds, high-fat meals (which cause increased GI secretions and biliary solubilization) will generally enhance drug dissolution. This is particularly true for weak acids and weak bases exhibiting high pKa values. However, weak bases with low pKa values may tend to precipitate in the small intestine and in the stomach when the $\mathrm{pH}$ of the GI contents is elevated due to food.

- Class III compounds are low permeability, high solubility. Therefore, issues associated with drug permeability can markedly affect drug absorption. Many of these compounds also exhibit region-dependent permeability. Accordingly, while food will not affect drug dissolution, it can alter drug absorption (e.g., viscosity of meal inducing a physical barrier to drug absorption). However, the mechanism and corresponding magnitude of food effects are variable across this class of compounds and therefore difficult to predict.

\section{MEMBRANE TRANSPORTERS}

The intestinal absorption of a drug product is largely governed by its dissolution characteristics, drug solubility and permeability, and the stability of the drug on exposure to the gut wall and its contents. However, there are numerous instances when the amount of drug reaching the hepatic portal circulation is inconsistent with expectations based on these properties. Oftentimes, unexpected bioavailability characteristics (either greater or lower than expected) can be attributed to the involvement of membrane transporter proteins. This observation has led to a surge of studies focusing on the identification and role of molecular transporters in modifying drug pharmacokinetics in both human and veterinary species.

Transport proteins have been implicated in both influx and efflux processes across a host of tissues, including the intestine, kidney, liver, and the central ner- vous system. ${ }^{88-91}$ Moreover, genetic variations in transporter gene sequences have been implicated in several severe genetic disorders. For this reason, Yan and Sadee $^{92}$ have developed a Web-accessible interactive human membrane transporter database that contains information such as genetic sequence, gene family, transporter structure, function and substrate, tissue distribution of the transporter, and genetic disorders associated with transporter sequence variants.

In general, membrane transporter activities tend to fall within the following classifications: ${ }^{88}$

- Facilitative transporters: passive transporters that assist in the passage of a single solute (uniporter) down an electrochemical gradient.

- Active transporters: transporters that move solutes against an electrochemical gradient and therefore must be coupled to the generation of free energy.

a. Ion pumps: active transporters coupled to an energyyielding chemical or a photochemical reaction. In most cases, these ion pumps result in a net movement of charges, generating a voltage difference across the membrane.

b. Secondary active transporters: use the voltage and ion gradients generated by the primary active transporters.

i. Cotransporters (symporters): move two or more different solutes in the same direction.

ii. Antiporters: move two or more different solutes in opposite directions, exploiting a chemical gradient for one of the solutes.

Table I contains examples of transporter families and the substrates whose intestinal absorption is believed to be linked in some manner to carrier-mediated transport.

The intestinal location of these transporters appears to be site specific. For example, transporter-mediated iron absorption occurs primarily within the upper duodenum while vitamin $\mathrm{B}_{12}$ absorption occurs in the terminal ileum. ${ }^{95}$ Additional specificity is conferred by apical to basal differences in transporter distribution. ${ }^{94}$ While the vast majority of transporters are located on apical membrane surfaces, some exist primarily on basolateral membrane surfaces. The latter include the $\mathrm{Na}^{+} / \mathrm{A}$ amino acid transporter, $\mathrm{Na}^{+} / \mathrm{ASC}$ amino acid transporter, GLUT2 hexose transporter, and $\mathrm{Na}^{+}-$ independent folic acid transporter. In addition, others may be found on either membrane surface, including $\mathrm{y}+$ amino acid transporters, $\mathrm{Na}^{+} / \mathrm{H}^{+}$antiporters, and an inorganic phosphate transporter.

Some drugs act as a substrate for multiple transporter systems, as is the case with several anionic $\beta$-lactams. ${ }^{96}$ In these situations, absorption is compli- 
Table I Transporters and Their Substrates ${ }^{90,93,94}$

\begin{tabular}{ll}
\hline \hline Transporter & \\
\hline $\begin{array}{l}\text { Lipid transporters/bile acid transporters } \\
\begin{array}{l}\text { Monocarboxylate transporters (organic anionic } \\
\text { transporters) }\end{array}\end{array}$ & $\begin{array}{l}\text { Fatty acids, cholesterol, (lipophilic drug?) } \\
\text { Salicyclic acid, pravastatin, NSAIDs, some fluroquinolones }\end{array}$ \\
$\begin{array}{l}\text { Organic cation transporters } \\
\text { Eucleoside transporter }\end{array}$ & $\begin{array}{l}\text { Epinephrine, choline, dopamine, guanidine, antiarrhythmics, several } \\
\text { antihistaminics }\end{array}$ \\
Intestinal dipeptide transporter & Nucleoside analogues used as antiviral and anticancer compounds \\
& $\begin{array}{l}\text {-lactam antibiotics, angiotensin-converting enzyme inhibitors, } \\
\text { thrombin inhibitors, thyrotropic-releasing hormone }\end{array}$ \\
Amino acid transporters & Gabapentin, baclofen, L-alpha-methyl dopa, L-dopa \\
Vitamin transporters & Valproic acid, salicylic acid, penicillins, methotrexate \\
Phosphate transporter & Fosfomycin, phosphonoacetic acid, phosphopropionic acid \\
P-glycoprotein (P-gp) & Etopside, vincristine, paclitaxel, ofloxacin, ciprofloxacin, cyclosporin, \\
& peptides, some organic cations, vinblastine \\
\hline
\end{tabular}

cated by drug affinity for both influx and efflux mechanisms. Therefore, any number of factors may be capable of influencing drug bioavailability.

Drug exsorption has been associated with a wide range of substances and a host of potential transporters. Efflux systems have been implicated in the intestinal membrane transport of organic anions (such as some cephalosporins, $\beta$-lactams, and fluroquinolones), glucuronide conjugates (presumably via apical membrane MRP2 transporter molecules), prostaglandins, and certain ester prodrugs. ${ }^{97-99}$ Intestinal secretion of Phase II metabolites may also be subject to binding and transport via the breast cancer resistance protein (BRCP), an ATP-binding cassette "half-transporter" responsible for extruding compounds such as topetecan across the luminal surface of the small intestine. ${ }^{99}$

Due to their broad range of substrate specificity, much of the recent research has focused on P-gp and the dipeptide transporter, PepT1. Accordingly, the remaining portion of this review will concentrate on these two transporter systems.

\section{PepT1}

The acidic $\mathrm{pH}$ generated by the brush-border $\mathrm{Na}^{+} / \mathrm{H}^{+}$ exchanger serves as the driving force for intestinal absorption of dipeptides, tripeptides, and peptoid drugs. ${ }^{88,93}$ However, while penetration of the apical membrane appears to depend on an apical $\mathrm{H}^{+} /$dipeptide transporter (PepT1), after entering the enterocyte, those proteins that are resistant to hydrolysis by intracellular peptidases are transported across the basolateral mem- brane by an $\mathrm{H}^{+}$-independent transporter, possibly PepT2. ${ }^{93}$ PepT1 is thought to exist on the apical membrane while the related PepT2 is thought to be localized on the basolateral membrane surface. ${ }^{94}$

The density of PepT1 increases from the duodenum to the ileum, being most abundant at the villus tip. Its expression is regulated by nutritional status, increasing in the presence of starvation. It is also relatively unaffected by a variety of drugs (such as 5-fluorouracil) that can adversely affect the function of other transporter systems. This observation has raised the suggestion that drugs whose absorption is linked to PepT1 may exhibit less variability during a course of therapy than would compounds whose absorption is associated with a less robust transporter mechanism. ${ }^{90}$

PepT1 possess two putative sites for phosphorylation by protein kinase $\mathrm{C}$, with protein kinase $\mathrm{C}$ activation suppressing peptide transport activity in Caco-2 cells. ${ }^{100}$ PepT1 is also negatively affected by an increase in the level of cAMP, presumably a consequence of a cAMP-induced stimulation of protein kinase C. ${ }^{101}$

Certain PepT1 substrate structure-activity relationships have been identified. Accordingly, while some exceptions do occur (e.g., several angiotensinconverting enzyme inhibitors), most substrates exhibit the following features: ${ }^{93,102,103}$

- a free C-terminal carboxyl group or a group capable of hydrogen bond formation,

- an amino group or a weakly basic group at the N-terminus, 
- highest affinity is associated with molecules that exist as zwitterions,

- a C-terminal amino acid in its L-configuration.

Compounds absorbed via the activity of dipeptide transporters exhibit saturable absorption. Consequently, substrate intestinal permeability $\left(\mathrm{P}_{\mathrm{w}}\right)$ can generally be described by one of the two following equations: ${ }^{104}$

$$
\mathrm{P}_{\mathrm{w}}=\mathrm{J}_{\max } /\left(\mathrm{K}_{\mathrm{m}}+\mathrm{C}_{\mathrm{w}}\right)+\mathrm{P}_{\mathrm{m}}
$$

or

$$
\mathrm{P}_{\mathrm{w}}=\mathrm{P}_{\mathrm{c}} /\left[1+\left(\mathrm{C}_{\mathrm{w}} / \mathrm{K}_{\mathrm{m}}\right)\right]+\mathrm{P}_{\mathrm{m}},
$$

where $\mathrm{J}_{\max }$ is the maximum transport rate, $\mathrm{C}_{\mathrm{w}}$ is the intestinal wall concentration, $\mathrm{K}_{\mathrm{m}}$ is the molar concentration of substrate at $1 / 2 \mathrm{~J}_{\max }, \mathrm{P}_{\mathrm{c}}$ is the permeability defined by the carrier-mediated transport, and $\mathrm{P}_{\mathrm{m}}$ is the intestinal permeability attributable to passive diffusion.

The central nervous system may play a role in stimulating intestinal PepT1 activity. ${ }^{105}$ In this regard, $\alpha_{2}$-adrenergic stimulation was found to enhance Caco-2 cell substrate absorption by increasing the translocation of the cytoplasmic transporter molecule to the apical membrane. It did not appear to act by altering transporter binding affinity. ${ }^{106}$ Although the exact mechanism for this apparent increase in translocation was not determined, it is believed to involve a cascade of events modulated by the G-proteins. G-proteins are responsible for regulating the trafficking of a number of transporters. ${ }^{107,108}$ However, it is unclear if these events could be translated to in vivo conditions since $\alpha_{2}$-adrenergic receptors are abundant in crypt cells (where PepT1 amounts are low) and are scarce in villus cells (where PepT1 amounts are high). ${ }^{109-111}$ Nevertheless, Berlioz et al ${ }^{105,106}$ noted that based on the work of Sundaram, ${ }^{112}$ the density of $\alpha_{2}$-adrenergic receptors in the villi might be sufficient to stimulate PepT1.

While traditional efforts to increase drug bioavailability have focused on drug solubility and permeability, recent strategies have focused on the development of prodrugs as a strategy for improving drug absorption. By targeting broad-spectrum transporters such as PepT1, drug absorption can be markedly enhanced. ${ }^{94}$ Once transported into the enterocyte, cytosolic enzymes convert the prodrug to its active form. ${ }^{90,94}$ Thus, by developing formulations that use the inherent physiological attributes of the enterocyte, the absorption of otherwise poorly bioavailable compounds can be markedly improved.

\section{ATP-Binding Cassette Transporter Proteins}

Another family of proteins whose impact on drug absorption is currently under intense investigation is the ATP-binding cassette (ABC) transporters. Based on conserved sequences, there are estimated to be approximately 48 ABC transporters of human cells. Mutations of these genes have been associated with the development of disease such as cystic fibrosis and obstetric cholestasis. Overexpression of these transporters has been implicated in various forms of drug resistance. ${ }^{113}$

A subfamily of $\mathrm{ABC}$ transporters is the multidrug resistance proteins (MRP). The MRP-associated gene family consists of seven members: MRP1, MRP2, MRP3, MRP43, MRP5, MRP6, and MRP7 ${ }^{89,114}$ Numerous names may be applied to the same protein. For example, MRP1 = ABCC1 = MRP; MRP2 = ABCC2 = cMOAT (canalicular multispecific organic anion transporter); $\mathrm{MRP} 3=$ ABCC3 $=$ MOAT-D = cMOAT-2; MRT4 $=$ ABCC4 $=$ MOAT-B; MRP5 = ABCC5 = MOAT-C $=$ pABC11; MRP6 = ABCC6 = MLP-1. These transporters differ both in terms of substrate specificity and in primary location within the body. ${ }^{89}$

In the gut, the MRP1 gene product located at the apical surface membrane, P-gp, serves as an effective barrier to the intestinal absorption of numerous substrates. ${ }^{115}$ It also acts as a highly efficient mechanism for transporting a variety of substances from the blood back into the intestinal tract. ${ }^{116} \mathrm{P}$-gp is located on the apical surfaces of many organs, including the bladder, kidney, brain, liver, lungs, pancreas, stomach, spleen, esophagus, and the large and small intestines. ${ }^{117,118} \mathrm{In}$ the intestine, the ratio of fluxes from the basolateral to apical versus the apical to basolateral direction ranges from 1.4 to 19.8 , depending on location within the GI tract. $^{115}$

P-gp uses ATP-derived energy to fuel the active efflux of its substrates. Although not the sole energydependent secretory mechanism affecting drug bioavailability, ${ }^{119} \mathrm{P}$-gp appears to have the most widespread importance due to its high intestinal concentration, its location within the intestine, and its broad substrate specificity. P-gp is located on the villus tip of the apical brush-border membrane, with minimal or no levels found within the intestinal crypts. ${ }^{120}$ Its activity tends to increase progressively from the stomach to the colon in humans, ${ }^{121}$ a consideration when developing sustained-release dosage forms.

ABC transporter proteins share a common molecular structure. This includes two large transmembrane domains (forming a pathway through which the solutes 
move) and two nucleotide binding sites. The transmembrane domain proteins are composed of multiple membrane-spanning segments (alpha helices), housing the substrate binding sites. The nucleotide binding sites are located at the cytoplasmic membrane surface and are responsible for coupling ATP hydrolysis with substrate translocation. The nucleotide binding sites appear to be linked by a short bridge of intracellular transmembrane domain loops, and it is believed that this bridge is responsible for the transfer of signals between the nucleotide binding site and the membrane-spanning proteins. ${ }^{113}$

Transmembrane proteins form a chamber that serves as an opening to the external aqueous environment and through which lipophilic substrates are believed to be extracted. This protein is also believed to form two large side entrances between the membrane proteins and the inner bilayer leaflet, and it is through these side entrances that small hydrophilic molecules may gain access to the P-gp molecule. ${ }^{113,122}$ A dramatic conformational change in the transmembrane domain protein is believed to occur on the binding of ATP to the nucleotide binding site, and it is the energy of this binding rather than the hydrolysis itself that may provide the initial energy for the substrate translocation. The conformational change is thought to also result in reduced binding site affinity, binding site reorientation, and a reduction in substrate affinity as the binding site is exposed to the aqueous chamber contents. This results in substrate release at the basal membrane surface. Subsequent hydrolysis and ADP/Pi release return the transporter protein to its original configuration. ${ }^{113}$

P-gp has been described as having at least four binding sites that allosterically communicate in a negative heterotropic manner. One site appears to act solely as a regulatory site, binding modulator but not transporter substances. At least three sites are associated with drug transport, with one of these three acting as both a transporter and a regulator. Each site is proposed to exist in either a high- or low-affinity state, with the allosteric interaction between sites altering the equilibrium between these states. ${ }^{123}$ There is also evidence that P-gp substrate affinity may vary as a function of intestinal site. ${ }^{124}$

Upon studying the structure-activity relationship of P-gp substrates, several points were noted. ${ }^{125}$ First, membrane partitioning is the rate-limiting step in the binding of substrates. Accordingly, hydrophobic interactions play a predominant role for membrane partitioning. However, numerous hydrophilic molecules are also actively transported, most probably reflecting the multiple potential points of entry to this transporter protein. Substrate affinity does not appear to be affected by molecular charge since there are examples of neutral, positively charged, and negatively charged molecules that are effectively carried by this transporter. ${ }^{99}$

Second, a compound must possess the ability to undergo hydrogen bonding with the transporter as a mechanism for activating the ATPase. The number and strength of these hydrogen bonds determine the dissociation of the P-gp-substrate complex. The binding of compounds with a high number of hydrogen bond acceptor patterns can lead to a lowering of the ATPase activation. Accordingly, the rate of hydrolysis appears to be indirectly proportional to the number and strength of hydrogen bond acceptor patterns per compound. If two substrates are simultaneously applied to the P-gp, the compound with the higher potential to form hydrogen bonds with P-gp will act as an inhibitor for the other. ${ }^{125}$

Barrier functions are markedly enhanced by the co-location of metabolizing enzymes and multidrug resistance proteins. ${ }^{117,126}$ Cytochrome P450 (CYP) 3A and P-gp are often colocated on the apical surfaces of small intestinal villi, exhibiting overlapping substrate specificity and shared inducers and inhibitors. Via their coordinated activities, drugs that are CYP3A substrates are continually cycled between the enterocyte and the gut lumen, thereby maximizing the extent of drug exposure to the catabolizing enzyme. Upon P-gp inhibition, the drug undergoes only a single exposure to the enzyme, leading to a decrease in drug degradation and higher oral bioavailability. Nevertheless, despite their closely aligned relationship, there appears to be independent genetic regulation of these proteins, as evidenced by the lack of correlation in the magnitude of the phenotypic expression of CYP3A and P-gp across individuals. ${ }^{27}$

Considering the potential impact of P-gp and CYP3A activity on drug bioavailability, Benet et $\mathrm{al}^{117}$ observed that the fraction of drug absorbed could be predicted by the following equations:

$$
\mathrm{F}_{\text {oral }}=\mathrm{F}_{\mathrm{a}} \bullet \mathrm{F}_{\mathrm{g}} \bullet \mathrm{F}_{\mathrm{h}}
$$

where

$$
\begin{aligned}
\mathrm{F}_{\text {oral }}= & \text { the oral bioavailability of a compound. } \\
\mathrm{F}_{\mathrm{a}}= & \text { the fraction of the oral dose that gets } \\
& \text { absorbed. } \\
\mathrm{F}_{\mathrm{g}} \quad= & \text { the fraction of a dose that passes through the } \\
& \text { gut into the hepatic portal blood without } \\
& \text { being metabolized. } \mathrm{F}_{\mathrm{g}} \text { can also be described } \\
& \text { as 1-ER (where } \mathrm{ER}_{\mathrm{g}} \text { is the gut extraction ratio). } \\
\mathrm{F}_{\mathrm{h}} \quad= & \text { the fraction of a dose that is not metabolized }
\end{aligned}
$$


on first pass through the liver. $\mathrm{F}_{\mathrm{h}}$ can also be described as $1-\mathrm{ER}_{\mathrm{h}}$ (where $\mathrm{ER}_{\mathrm{h}}$ is the hepatic extraction ratio).

and

$$
\begin{gathered}
\mathrm{ER}_{\mathrm{g}}=\mathrm{k}_{\mathrm{mg}} /\left(\mathrm{k}_{\mathrm{mg}} \bullet \mathrm{k}_{\mathrm{a}}\right), \\
\mathrm{ER}_{\mathrm{h}}=\mathrm{CL}_{\mathrm{h}} / \mathrm{Q}_{\mathrm{h}},
\end{gathered}
$$

where $\mathrm{k}_{\mathrm{a}}$ is the absorption rate constant for the drug entering the blood from the intestine, $\mathrm{k}_{\mathrm{mg}}$ is the rate constant for drug metabolism in the gut, $\mathrm{CL}_{\mathrm{h}}$ is the hepatic blood clearance, and $\mathrm{Q}_{\mathrm{h}}$ is the hepatic blood flow.

Ultimately, $\mathrm{F}_{\text {oral }}$ can be modified by concomitant exposure to substances that act as inducers or inhibitors of these metabolic processes. P-gp inhibitors and inducers act by altering $\mathrm{k}_{\mathrm{a}}$. The absence of a corresponding change in $\mathrm{t}_{\max }$ can be explained by the concomitant change in substrate elimination from the systemic circulation. ${ }^{117}$

As evidenced by drugs that are metabolically inert such as talinolol ${ }^{128}$ and fexofenadine, ${ }^{129} \mathrm{P}$-gp contributes to dose-dependent oral bioavailability such that bioavailability can increase solely due to efflux pump saturation. In addition, intestinal absorption of substrates can be increased through substrate competition, ATP depletion, or changes in membrane fluidity. ${ }^{130,131}$ Numerous inhibitors such as verapamil, quinidine, and nifedipine have also shown to increase the bioavailability of P-gp substrates such as etopside, paclitaxel, and vinblastine ${ }^{94}$ Conversely, P-gp inducers such as rifampin can decrease the bioavailability of certain compounds by increasing total gut activity of this efflux protein. ${ }^{132}$

The importance of P-gp may be most clearly seen by the impact of the genetic mutations. In mice, the mdr1a-/-genotype results in "knockout" mice that exhibit a total absence of gut P-gp activity. These mice were used to examine the P-gp role in limiting the intestinal absorption of paclitaxel. ${ }^{133}$ Paclitaxel AUC values after oral administration in wild-type mice (mdr1a+/+) versus knockout mice (mdr1a-/-) were $11 \%$ and $35 \%$, respectively. Intestinal secretion following intravenous administration was practically eliminated in knockout mice, even though $40 \%$ of the dose underwent intestinal secretion in the wild-type mice. Similar differences in wild-type versus knockout mice bioavailability were observed for such compounds as vinblastine, digoxin, indinavir, and talinolol. ${ }^{91}$ An effect corresponding to the mdr1a-/-genetic variant in mice was observed in humans, where certain variations in the MDR1 gene have been shown to alter both the gut expression of P-gp and the oral bioavailability of P-gp substrates. ${ }^{134}$
Permeability enhancers such as the bile salt sodium deoxycholate,${ }^{135}$ fatty acids such as sodium caprate, ${ }^{135}$ and surfactants ${ }^{131}$ such as polysorbate $80,{ }^{136}$ Cremophor $\mathrm{EL},{ }^{137}$ and vitamin $\mathrm{E}^{138}$ can alter P-gp activity. The mechanism by which these substances interact with P-gp appears, at least in part, to involve a change in membrane fluidity.

Dudeja et al ${ }^{131}$ provided data suggesting that surfactants such as Solutol HS-15, Tween 40, and Cremophor EL decrease lipid fluidity of both intact cells and isolated crude plasma membranes. Similarly, the ATPase activity of the sarcoplasmic reticulum calcium transporter, $\mathrm{Ca}^{2+}$-ATPase, is decreased in the presence of lower membrane fluidity. ${ }^{139}$ Furthermore, multidrugresistant Chinese hamster ovary cells were shown to exhibit lower membrane fluidity than did their drug-sensitive counterpart. ${ }^{140}$

In contrast, membrane fluidity was found to increase in the presence of ether, benzyl alcohol, Tween 20 , Triton X-100, and verapmil, and this increase in fluidity was correlated with the inhibition of P-gp ATPase activity in multidrug-resistant hamster ovary cells. ${ }^{141}$ Moreover, the bile salt, taurochenodeoxycholate, and verapamil increased membrane fluidity and decreased P-gp activity in multidrug-resistant hamster ovary cells. ${ }^{142}$

Although the reasons for these discrepancies are not obvious, each of these studies consistently noted that surfactants could alter drug efflux. The combination of efflux transporter inhibition, enhancement of transcellular diffusion, and facilitation of paracellular diffusion results in substantially increased oral drug bioavailability. Consequently, formulators are examining the use of these and other P-gp inhibitors as a formulation strategy for improving the absorption of poorly bioavailable compounds. ${ }^{99}$

\section{Other Transporter \\ Systems of Interest}

\section{Organic Anions and Cations}

An amphiphilic solute facilitator family with the capability of transporting organic anions and cations has been recently defined. ${ }^{143}$ Although their full scope of intestinal significance has yet to be determined, members of this family are diverse, exhibiting a number of characteristics, including the following: ${ }^{.43}$

- a sodium-independent thiamin transporter;

- a sodium-independent and potential-dependent transporter that mediates absorption of tyramine, tryptamine, and disopyramide; 
- a sodium and potential-independent transporter that mediates the absorption of choline and may be involved in the secretion of organic ions through an organic cationic exchange mechanism;

- a proton/cation antiporter;

- a P-gp that mediates secretion of hydrophobic cations;

- a polyamine transporter.

\section{Lipid and Cholesterol Transporters}

Also of interest is the absorption of lipophilic compounds such as long chain fatty acids (LCFA) and cholesterol. Certainly, one of the pivotal steps in the absorption of nonpolar lipids is its micellar solubilization in the unstirred water layer of the intestine, generally by bile salts. ${ }^{144}$ Upon contacting the brush-border membrane, the high lipophilicity of these compounds should allow for absorption to occur simply by passive diffusion. However, recent evidence suggests that although cholesterol and LCFAs are expected to freely diffuse through the enterocyte membrane, these compounds exhibit saturable absorption. Putative transporter proteins are concentrated in the stomach and on the villus tips of the distal small intestine of rats. ${ }^{144,145}$ This is consistent with earlier findings that substances such as linoleate appear to be absorbed via a carriermediated process at low concentrations and by passive diffusion after carrier saturation has occurred. ${ }^{146}$ Moreover, there may be several binding proteins influencing the transport of lipophilic compounds. ${ }^{147}$

Intestinal cholesterol absorption is a complex process, involving numerous enzymes and transporter systems. ${ }^{148}$ Thurnhofer and Hauser ${ }^{149}$ successfully identified a cholesterol-binding transport protein in the small intestinal brush-border membrane that helps transport cholesterol into the enterocyte. Moreover, absorption is dependent on the maintenance of the concentration gradient within the enterocyte. In this regard, acyl CoA:cholesterol aceytltransferase (ACAT) appears to be responsible for cholesterol ester synthesis, the latter of which may be accountable for maintaining an intracellular diffusion gradient for free dietary cholesterol in the presence of a high-cholesterol diet. $^{146,150}$

In addition to carrier-mediate processes, cholesterol absorption also appears to be affected by the action of multidrug-resistant efflux proteins, the latter appearing to be the same transporter responsible for prohibiting the absorption of plant sterol. ${ }^{146}$ It was noted that human mutations in ABC transporter genes are responsible for the development of sitosterolemia. Two of these genes are expressed at highest levels in the gut and intestine and appear to result in sterol accumulation and the development of atherosclerosis. ${ }^{151}$ Moreover, animal model studies reveal the impact of genetic mutations on the presence of abnormal cholesterol and bile salt metabolism. ${ }^{148}$ Therefore, given the growing recognition of the importance of transporters in maintaining cholesterol homeostasis, it is evident that these transporters are becoming a target for new drug therapies.

\section{CLOSING STATEMENT}

Drug absorption is a complex process that reflects the potential interaction of a host of variables, both physicochemical and physiologic. The skilled formulation chemist artfully manipulates product properties by the use of manufacturing methods and product excipients to increase the solubility and permeability of problematic compounds. However, physiological variables, both endogenous (such as age, disease state, phenotype, and gender) and exogenous (such as food consumption, nutritional status, concomitant medication, and environmental exposure to other xenobiotics), can markedly affect the absorption characteristics of a compound. By understanding the physicochemical properties of a compound (such as its pKa, $\log \mathrm{P}$ value, molecular flexibility, hydrogen bonding dynamics, and molecular weight) and by recognizing its affinity for the various enzymes systems and transporter mechanisms, we can predict with some degree of accuracy a product's expected bioavailability. Thus, through an awareness of a drug's BCS characteristics and the physiological processes affecting drug absorption, the pharmaceutical scientist can better predict drug absorption and develop formulations that can maximize product availability. Finally, this information can be invaluable when considering the drug's prescribability in the face of varying patient physiological status, phenotype, age, gender, or lifestyle.

With regard to membrane transporters, these mechanisms and the factors that can alter their activity have been the recent focus of much research activity. Accordingly, there appears to be a rapid rise in the number of transporter molecules being identified across all organs systems. These carrier-mediated transport proteins are now being targeted as mechanisms for improving oral drug bioavailability, such as the synthesis of prodrugs to improve binding site affinity, concomitant administration of substances that enhance the activity of carrier-mediated influx systems, or by including substances that act as inhibitors of efflux transporters. By identifying the intestinal location of specific transporter molecules, directed drug delivery can be used to improve drug bioavailability. Moreover, 
an understanding of the genetic polymorphism of drug transporters is hoped to enable scientists to better design drugs that are targeted for improved bioavailability within select patient populations and to understand the causes for various malabsorption syndromes. It is hoped that by understanding some of the genetic mutations seen in the patient population, scientists can better accommodate phenotypic variability observed across clinical practices and treat conditions resulting from defective transport systems.

\section{REFERENCES}

1. Midha KK, Rawson MJ, Hubbard JW: Prescribability and switchability of highly variable drugs and drug products. J Control Release 1999;62:33-40.

2. Amidon GL, Lennernas H, Shah VP, Crison JR: A theoretical basis for a biopharmaceutic drug classification: the correlation of in vitro drug product dissolution and in vivo bioavailability. Pharm Res 1995; 12:413-420.

3. Lindahl A, Persson B, Ungell AL, Lennernas H: Surface activity concentration dependent intestinal permeability in the rat. Pharm Res 1999;16:97-102.

4. Lobenberg R, Amidon GL: Modern bioavailability, bioequivalence and biopharmaceutics classification system: new scientific approaches to international regulatory standards. Eur J Pharm Biopharm 2000;50:3-12.

5. Seydel JK, Schaper KJ: Quantitative structure-pharmacokinetic relationships and drug design. Pharmacol Ther 1982;15:131-182.

6. Carver PL, Fleisher D, Zhou SY, Kaul D, Kazanjian P, Li C: Meal composition effects on the oral bioavailability of indinavir in HIVinfected patients. Pharm Res 1999;16:718-724.

7. Fleisher D, Li C, Zhou Y, Pao LH, Karim A: Drug, meal and formulation interactions influencing drug absorption after oral administration. Clin Pharmacokinet 1999;36:233-254.

8. Sokoloski TD: Solutions and phase equilibria, in: Gennaro AR (ed.), Remington's Pharmaceutical Sciences. Easton, PA: Mack Publishing, 1985;207-229.

9. Stenberg P, Luthman K, Artursson P: Prediction of membrane permeability to peptides from calculated dynamic molecular surface properties. Pharm Res 1999;16:205-212.

10. Martini LG, Avontuur P, George A, Willson RJ, Crowley PJ: Solubility parameter and oral absorption. Eur J Pharm Biopharm 1999; 48:259-263.

11. Andrews CW, Bennett L, Yu LX: Predicting human oral bioavailability of a compound: development of a novel quantitative structure-bioavailability relationship. Pharm Res 2000;17:639-644.

12. Tieleman DP, Marrink SJ, Berendsen HJC: A computer perspective of membranes: molecular dynamics studies of lipid bilayer systems. Biochim Biophys Acta 1997;1331:235-270.

13. Palm K, Luthman K, Ungell A-L, Strandlund G, Artursson P: Correlation of drug absorption with molecular surface properties. $J$ Pharm Sci 1996;85:32-39.

14. Larhed AW, Artursson P, Bjork E: The influence of intestinal mucous components on the diffusion of drugs. Pharm Res 1998;15: 66-71.
15. Stenberg P, Luthman K, Artursson P: Virtual screening of intestinal drug permeability. J Control Release 2000;65:231-243.

16. Aungst BJ, Saitoh $H$ : Intestinal absorption barriers and transport mechanisms, including secretory transport, for a cyclic peptide, fibrinogen antagonist. Pharm Res 1996;13:114-119.

17. Palm K, Ros J, Grasjo J, Luthman K, Artursson P: Effect of molecular charge on intestinal epithelial drug transport. J Pharmacol Exp Therap 1999;291:435-443.

18. Lennernas H: Does fluid flow across the intestinal mucosa affect quantitative oral drug absorption? Is it time for a reevaluation? Pharm Res 1995;12:1573-1582.

19. Jackson MJ: Drug transport across gastrointestinal epithelia, in: Johnson LR (ed.), Physiology of the Gastrointestinal Tract, 2nd ed. New York: Raven, 1987.

20. He Y-L, Murby S, Warhurst G, Gifford L, Walker D, Ayrton J, et al: Species differences in size discrimination in the paracellular pathway reflected by oral bioavailability of poly(ethylene glycol) and D-peptides. J Pharm Sci 1998;87:626-633.

21. Yu LX, Crison JR, Lipka E, Amidon GL: Transport approaches to the biopharmaceutical design of oral drug delivery systems: prediction of intestinal absorption. Adv Drug Deliv Rev 1996;19:359-376.

22. Mitchell DY, Eusebio RA, Dunlap LE, Pallone KA, Nesbitt JD, Russell DA, et al: Risedronate gastrointestinal absorption is independent of site and rate of administration. Pharm Res 1998;15: 228-232.

23. Pao LH, Zhou SY, Cook C, Kararli T, Kirchhoff C, Truelove J, et al: Reduced systemic availability of an antiarrhythmic drug, bidisomide, with meal co-administration: relationship with regiondependent intestinal absorption. Pharm Res 1998;15:221-227.

24. Abdou HM: Dissolution, Bioavailability and Bioequivalence. Easton, PA: Mack Publishing, 1989.

25. Macheras P, Dokoumetzidis A: On the heterogeneity of drug dissolution and release. Pharm Res 2000;17:108-112.

26. Cussler EL: Diffusion: Mass Transfer in Fluid Systems. 2nd ed. New York: Cambridge University Press, 1997.

27. Yu LX: An integrated model for determining causes of poor oral drug absorption. Pharm Res 1999;16:1883-1887.

28. Dali MV, Carstensen JT: Effect of change in shape factor of a single crystal on its dissolution behavior. Pharm Res 1996;13:155-162.

29. Tiwary AK, Panpalia GM: Influence of crystal habit on trimethoprim suspension formulation. Pharm Res 1999;16:261-265.

30. Hossain M, Abramowitz W, Watrous BJ, Szpunar GJ, Ayres JW: Gastrointestinal transit of nondisintegrating, nonerodible oral dosage forms in pigs. Pharm Res 1990;7:1163-1166.

31. Dressman JB: Physiological aspects of the design of dissolution tests, in: Amidon G, Robinson J, Williams R (eds.), Scientific Foundations for Regulating Drug Product Quality. Alexandria, VA: AAPS Press, 1997;155-168.

32. Rekhi GS, Eddington ND, Fossler MJ, Schwartz P, Lesko LJ, Augsburger LL: Evaluation of in vitro release rate and in vivo absorption characteristics of four metoprolol tartrate immediate-release tablet formulations. Pharm Dev Technol 1997;2:11-24.

33. Eddington ND, Ashraf M, Augsburger LL, Leslie JL, Fossler MJ, Lesko L, et al: Identification of formulation and manufacturing variables that influence in vitro dissolution and in vivo bioavailability of propranolol hydrochloride tablets. Pharm Dev Technol 1998;3: 525-547. 
34. Piscitelli DA, Bigora S, Propst C, Goskonda S, Schwartz P, Lesko LJ, et al: The impact of formulation and process changes on in vitro dissolution and bioequivalence of piroxicam capsules. Pharm Dev Technol 1998;3:443-452.

35. Food and Drug Administration, Guidance for Industry: Guidance for industry: immediate release solid oral dosage forms: scale-up and postapproval changes: chemistry, manufacturing, and controls, in vitro dissolution testing, and in vivo bioequivalence documentation, November 1995 [Online]. Available: http://www.fda.gov/cder/ guidance/cmc5.pdf.

36. Lipka E, Amidon GL: Setting bioequivalence requirements for drug development based on preclinical data: optimizing oral drug delivery systems. J Control Release 1999;62:41-49.

37. Lin JH, Chiba M, Baillie TA: Is the role of the small intestine in first-pass metabolism overemphasized? Pharmacological Rev 1999;51:135-157.

38. Lin JH: Applications and limitations of interspecies scaling and in-vitro extrapolation in pharmacokinetics. Drug Metab Disp 1998; 26:1202-1212.

39. Yeh KE, Deutsch PJ, Haddix H, Hesney M, Hoagland V, Ju WD, et al: Single-dose pharmacokinetics of indinavir and the effect of food. Antimicrob Agents Chemother 1998;42:332-338.

40. Ito K, Kusuhara H, Sugiyama Y: Effects of intestinal CYP3A4 and P-glycoprotein on oral drug absorption: theoretical approach. Pharm Res 1999;16:225-231.

41. Lin JH, Chiba M, Chen I-W, Nishime JA, Deluna FA, Yamazaki M, et al: Effect of dexamethasone on the intestinal first-pass metabolism of indinavir in rats: evidence of cytochrome P-450 A and P-glycoprotein induction. Drug Metab Disp 1999;27:1187-1193.

42. Ilett KF, Tee LBG, Reeves PT, Minchin RF: Metabolism of drugs and other xenobiotics in the gut lumen and wall. Pharmacol Ther 1990;46:67-93.

43. Krishna DR, Klotz U: Extrahepatic metabolism of drugs in humans. Clin Pharmacokinetic 1994;26:144-160.

44. Kaminsky LS, Fasco MJ: Small intestinal cytochromes P450. Crit Rev Tox 1992;21:407-422.

45. Paine MF, Shen DD, Kunze KL, Perkins JD, Marsh CL, McVicar JP, et al: First-pass metabolism of midazolam by the human intestine. Clin Pharmacol Ther 1996;60:14-24.

46. Chesa-Jimenez J, Peris JE, Torres-Molina F, Granero L: Low bioavailability of amoxicillin in rats as a consequence of presystemic degradation in the intestine. Antimicrob Agents Chemother 1994;38:842-847.

47. Ducharme MP, Warbasse LH, Edwards DJ: Disposition of intravenous and oral cyclosporin after administration with grapefruit juice. Clin Pharmacol Ther 1995;57:485-491.

48. Benet LZ, Izumi T, Zhang Y, Silverman JA, Wacher VJ: Intestinal MDR transport proteins and P-450 enzymes as barriers to oral drug delivery. J Control Release 1999;62:25-31.

49. Wacher VJ, Silverman JA, Zhang Y, Benet LZ: Role of P-glycoprotein and cytochrome P450 3A in limiting oral absorption of peptides and peptidomimetics. J Pharm Sci 1998;87:1322-1330.

50. Davis LE, Neff CA, Baggot JD, Powers TE: Pharmacokinetics of chloramphenicol in domesticated animals. Am J Vet Res 1972;33: 2259-2266.

51. Aldercreutz H, Pulkkinen MO, Hamalainen EK, Korpela JT: Studies on the role of intestinal bacteria in metabolism of synthetic and natural steroid hormones. J Steroid Biochem 1984;20:217-229.
52. Lu HH, Thomas J, Fleisher D: Influence of D-glucose-induced water absorption on rat jejunal uptake of two passively absorbed drugs. $J$ Pharm Sci 1992;81:21-25.

53. Mancinelli L, Cronin M, Sadee W: Pharmacogenomics: the promise of personalized medicine. AAPS Pharmsci 2000;2(1):article 4.

54. Morgan ET, Sewer MB, Iber H, Gonzalez FJ, Lee YH, Tukey RH, et al: Physiological and pathophysiological regulation of cytochrome P450. Drug Metab Disp 1998;26:1232-1240.

55. Flockhart DA: Cytochrome P450 drug interaction table [Online]. Available: http://medicine.iupui.edu/flockhart/.

56. Devane J: Oral drug delivery technology: addressing the solubility/ permeability paradigm. Pharm Tech 1998;22:68-80.

57. Blume HH, Schug BS: The biopharmaceutics classification system (BCS): class III drugs-better candidates for BA/BE waiver? Eur J Pharm Sci 1999;9:117-121.

58. Poli JE: In vitro-in vivo relationship of several "immediate release" tablets containing a low permeability drug. Adv Exp Med Biol 1997;423:191-198.

59. Adkin DA, Davis SS, Sparrow RA, Huckle PD, Wilding JR: The effect of mannitol on the oral bioavailability of cimetidine. JPharm Sci 1995;84:1405-1409.

60. Koch KM, Parr AF, Tomlinson JJ, Sandefer EP, Digenis GA, Donn KH, Powell JR: Effect of sodium acid pyrophosphate on ranitidine bioavailability and gastrointestinal transit time. Pharm Res 1993;10:1027-1030.

61. Del Estal JL, Alvarez AI, Villaverde C, Coronel P, Fabra S, Prieto JG: Effect of surfactants on albendazole absorption. J Pharm Biomed Analysis 1991;9:1161-1164.

62. Woodcock DM, Linsenmeyer E, Chojnowski G, Kriegler AB, Nink $\mathrm{V}$, Webster LK, et al: Reversal of multidrug resistance by surfactants. Br J Cancer 1992;66:62-68.

63. Elllis AG, Crinis NA, Webster LK: Inhibition of etoposide elimination in the isolated perfused rat liver by Cremophor EL and Tween 80. Cancer Chemother Pharmacol 1996;38:81-87.

64. Monkhouse DC, Lach JL: Drug-excipient interactions. Can J Pharm Sci 1972;7:29-46.

65. Kalinkova GN: Studies of beneficial interactions between active medicaments and excipients in pharmaceutical formulations. Int $J$ Pharm 1999;187:1-15.

66. Pifferi G, Santoro P, Pedrani M: Review: quality and functionality of excipients. Il Farmaco 1999;4:1-14.

67. Grosvenor MP, Lofroth JE: Interaction between bile salts and beta-adrenergic receptor antagonists. Pharm Res 1995;12:682-686.

68. Oberle RL, Chen TS, Lloyd C, Barnett JL, Owyang C, Meyer J, Amidon GL: The influence of the interdigestive migrating myoelectric complex on the gastric emptying of liquids. Gastroenterology 1990;99:1275-1282.

69. Fleckenstein P: Migrating electrical spike activity in the fasting human small intestine. Am J Dig Dis 1978;23:769-775.

70. Code CF, Marlett JA: The interdigestive myoelectric complex of the stomach and small bowel of dogs. J Physiol 1975;246:289-309.

71. Sarna SK: Cyclic motor activity: migrating motor complex. Gastroenterology 1985;89:894-913.

72. Welling PG: Effect of food on bioavailability of drugs. Pharm Int 1985;1:14-18.

73. Karlsson J, Ungell A-L, Grasjo J, Arturrson P: Paracellular drug transport across intestinal epithelia: influence of charge and induced water efflux. Eur J Pharm Sci 1999;9:47-56. 
74. Fihn B-M, Sjoqvist A, Jodal M: Permeability of the rat small intestinal epithelium along villus-crypt axis: effects of glucose transport. Gastroenterology 2000;119:1029-1036.

75. Bijsma PB, Fihn BM, Sjoqvist A, Groot JA, Taminiau JAJM, Jodal M: Solvent drag mediated absorption of ${ }^{14} \mathrm{C}$-mannitol but not of ${ }^{51} \mathrm{Cr}$-EDTA in cat small intestine in vivo [abstract]. Gastroenterology 1995;108:A274.

76. Reppas C, Meyer JH, Sirois PJ, Dressman JB: Effect of hydroxypropylmethylcellulose on gastrointestinal transit and luminal viscosity in dogs. Gastroenterology 1991;100:1217-1223.

77. Rhie JK, Hayashi Y, Welage LS, Frens J, Wald RJ, Barnett JL, et al: Drug marker absorption in relation to pellet size, gastric motility and viscous meals in humans. Pharm Res 1998;15:233-238.

78. Wilkinson GR: The effects of diet, aging and disease-states on presystemic elimination and oral drug bioavailability in humans. Adv Drug Deliv Rev 1997;27:129-159.

79. Liedholm H, Wahlin-Boll E, Melander A: Mechanisms and variations in the food effect on propranolol bioavailability. Eur J Clin Pharmacol 1990;38:469-475.

80. Koch PA, Schultz CA, Wills RJ, Hallquist SL, Welling PG: Influence of food and fluid ingestion on aspirin bioavailability. J Pharm Sci 1978;67:1533-1535.

81. Degtyarenko KN, Fábián P: Directory of P450-containing systems [Online]. Available: http://www.icgeb.trieste.it/ p450srv/.

82. Russell TL, Berardi RR, Barnett JL, O’Sullivan TL, Wagner JG, Dressman JB: pH-related changes in the absorption of dipyridamole in the elderly. Pharm Res 1994;11:136-143.

83. Chin TWF, Loeb M, Fong IW: Effects of an acidic beverage (Coca-Cola) on absorption of ketoconazole. Antimicrob Agents Chemother 1995;39:1671-1675.

84. Kabanda L, Lefebve RA, Van Bree HJ, Remon JP: In vitro and in vivo evaluation in dogs and pigs of a hydrophilic matrix containing propylthiouracil. Pharm Res 1994;11:1663-1668.

85. Menzies IS, Zuckerman MJ, Nukajam WS, Somasundaram SG, Murphy B, Jenkins AP, et al: Geography of intestinal permeability and absorption. Gut 1999;44:483-489.

86. Kalampokis A, Argyrakis P, Macheras P: Heterogeneous tube model for the study of small intestinal transit flow. Pharm Res 1999; 16:87-91

87. Macheras P, Argyrakis P: Gastrointestinal drug absorption: is it time to consider heterogeneity as well as homogeneity? Pharm Res 1997;14:842-847.

88. Saddee W, Drubbisch V, Amidon GL: Biology of membrane transport protein. Pharm Res 1995;12:1823-1837.

89. Borst P, Evers R, Kool M, Wijnhold J: The multidrug resistance protein family. Biochem Biophys Acta 1999;1461:347-357.

90. Lee VHL: Membrane transporters. Eur J Pharm Sci 2000; 11(Suppl. 2):S41-S50.

91. Ayrton A, Morgan P: Role of transport proteins in drug absorption, distribution and excretion. Xenobiotica 2001;31:469-497.

92. Yan Q, Sadee W: Human membrane transporter database: a Web-accessible relational database for drug transport studies and pharmacogenomics. AAPS PharmSci 2000;2(3):article 20.

93. Yang CY, Dantzip AH, Pidgeon C: Intestinal peptide transport system and oral drug availability. Pharm Res 1999;16:1331-1343.

94. Oh D-M, Han H-K, Amidon GL: Drug transport and targeting, in: Amidon GL, Sadee W (eds.), Membrane Transporters as Drug Targets. New York: Kluwer Academic/Plenum, 1999;59-88.
95. Iseki K, Sugawara M, Sato K, Naasani I, Hayakawa T, Kobayashi M, et al: Multiplicity of the H+-dependent transport mechanism of dipeptide and anionicbeta-lactam antibiotic ceftibuten in rat intestinal brush-border membrane. J Pharmacol Exp Ther 1999;289:66-71.

96. Sellin JH: The pathophysiology of diarrhea, in: Schultz SG, Andreoli TE, Brown AM, Fambrough DM, Hoffman JF, Welsh MJ (eds.), Molecular Biology of Membrane Transport Disorders. New York: Plenum, 1996;541-563.

97. Saitoh H, Gerard C, Aungst BJ: The secretory intestinal transport of some beta-lactams antibiotics and anionic compounds: a mechanism contributing to poor drug absorption. J Pharmacol Exp Ther 1996;278:205-211.

98. Suzuki H, Sugiyama Y: Role of metabolic enzymes and efflux transporters in the absorption of drugs from the small intestine. Eur $J$ Pharm Sci 2000;12:3-12.

99. Wagner D, Spahn-Langguth $H$, Hanafy A, Koggel A, Langguth P: Intestinal drug efflux: formulation and food effects. Adv Drug Deliv Rev 2001;50:S13-S31.

100. Brandsch M, Miyamoto Y, Ganapathy V, Leibach FH: Expression and protein kinase $\mathrm{C}$-dependent regulation of peptide/H 1 co-transport system in the Caco-2 human colon carcinoma cell line. Biochem J 1994;299:253-260.

101. Muller U, Brandsch M, Prasad P, Fei Y, Ganapathy V, Leibach F: Inhibition of the $\mathrm{H}^{+}$/peptide cotransporter in the human intestinal cell line Caco-2 by cyclic AMP. Biochem Biophys Res Commun 1996; 218:461-465.

102. Moore VA, Irwin WJ, Timmins P, Lambert PS, Chong S, Dando SA, et al: A rapid screening system to determine drug affinities for the intestinal dipeptide transporter 2: affinities of ACE inhibitors. Int $J$ Pharm 2000;210:29-44.

103. Payne JW, Grail BM, Gupta S, Ladbury JE, Marshall NJ, O’Brien $\mathrm{R}$, et al: Structural basis for recognition of dipeptides by peptide transporters. Arch Biochem Biophys 2000;384:9-23.

104. Johnson DA, Amidon GL: Determination of intrinsic membrane transport parameters from perfused intestine experiments: a boundary layer approach to estimating the aqueous and unbiased membrane permeabilities. J Theor Biol 1988;131:93-106.

105. Berlioz F, Julien S, Tsocas A, Chariot J, Carbon C, Farinotti R, et al: Neural modulation of cephalexin intestinal absorption through the di- and tripeptide brush border transporter of rat jejunum in vivo. J Pharmacol Exp Ther 1999;288:1037-1044.

106. Berlioz F, Maoret JJ, Paris H, Laburthe M, Farinotti R, Roze C: Alpha(2)-adrenergic receptors stimulate oligopeptide transport in a human intestinal cell line. J Pharmacol Exp Ther 2000;294:466-472.

107. Schwiebert EM, Gesek F, Ercolani L, Wjasow C, Gruenert DC, Karlson K, et al: Heterotrimeric $\mathrm{G}$ proteins, vesicle trafficking, and CFTR Cl 2 channels. Am J Physiol 1994;267:C272-C281.

108. Valenti G, Procino G, Liebenhoff U, Frigeri A, Benedetti PA, Ahnert-Hilger $\mathrm{G}$, et al: A heterotrimeric $\mathrm{G}$ protein of the $\mathrm{Gi}$ family is required for cAMP-triggered trafficking of aquaporin 2 in kidney epithelial cells. J Biol Chem 1998;273:22627-22634.

109. Paris H, Voisin T, Remaury A, Rouyer-Fessard C, Daviaud D, Langin D, et al: Alpha2-adrenoreceptor in rat jejunum epithelial cells: characterization with $\left[{ }^{3} \mathrm{H}\right] \mathrm{RX} 821002$ and distribution along the villus-crypt axis. J Pharmacol Exp Ther 1990;254:888-893.

110. Valet P, Senard JM, Devedjian JC, Planat V, Salomon R, Voisin T, et al: Characterization and distribution of alpha2-adrenergic receptors in the human intestinal mucosa. JClin Invest 1993;91:2049-2057. 
111. Ogihara H, Saito H, Shin BC, Terado T, Takenoshita S, Nagamachi Y, et al: Immuno-localization of $\mathrm{H}^{+} /$peptide cotransporter in rat digestive tract. Biochem Biophys Res Commun 1996;220: 848-852.

112. Sundaram U: Mechanism of intestinal absorption. Effect of clonidine on rabbit ileal villus and crypt cells. J Clin Invest 1995;95:2187-2194.

113. Higgins $\mathrm{CF}$, Linton $\mathrm{KJ}$ : The xyz of $\mathrm{ABC}$ transporters. Science 2001;93:1782-1784.

114. Hopper E, Belinsky MG, Zeng H, Tosolini A, Testa JR, Kruh GD: Analysis of the structure and expression pattern of MRP7 (ABCC10), a new member of the MRP subfamily. Cancer Lett 2001;162:181-191.

115. Makhey VD, Guo A, Norris DA, Hu P, Yan J, Sinko PJ: Characterization of the regional intestinal kinetics of drug efflux in rat and human intestine and in Caco-2 cells. Pharm Res 1998;15:1160-1167.

116. Arimori K, Nakano M: Drug exsorption from blood into the gastrointestinal tract. Pharm Res 1998;15:371-376.

117. Benet LZ, Izumi T, Zhang Y, Silverman JA, Wacher VJ: Intestinal MDR transport proteins and P450 enzyme as barriers to oral drug delivery. J Cont Rel 1999;62:23-31.

118. Dresser MJ: The MDR1, C3435T polymorphism: effects on P-glycoprotein expression/function and clinical consequences. AAPS PharmSci 3(special volume) [Online]. Available: http://www.aapspharmsci.org/scientificjournals/pharmsci/virtual/ pgpx/dresser1.html.

119. Saitoh H, Fujisak H, Aungst BJ, and Miyazaki K: Restricted intestinal absorption of some beta-lactam antibiotics by an energydependent efflux system in rat intestine. Pharm Res 1997;14: 645-649.

120. Watkins PB: The barrier function of CYP3A4 and P-glycoprotein in the small bowel. Adv Drug Deliv Rev 1997;27:161-170.

121. Fricker G, Drewe J, Howyler J, Gutmann H, Beglinger C: Relevance of P-glycoprotein for the enteral absorption of cyclosporin A: in-vitro-in-vivo correlation. Br J Pharmacol 1996;118:1841-1847.

122. Rosenberg MF, Velarde G, Ford RC, Martin C, Berridge G, Kerr ID, et al: Repacking of the transmembrane domains of P-glycoprotein during the transport ATPase cycle. EMBO J 2001;20:5615-5625.

123. Martin C, Berridge G, Higgins CF, Mistry P, Charleton P, Callaghan R: Communication between multiple drug binding sites on P-glycoprotein. Mol Pharmacol 2000;58:624-632.

124. Saitoh H, Aungst BJ: Possible involvement of multiple P-glycoprotein-mediated efflux systems in the transport of verapamil and other organic cations across rat intestine. Pharm Res 1995; 12:1304-1310.

125. Seelig A, Landwojtowicz E: Structure-activity relationship of P-glycoprotein substrates and modifiers. Eur J Pharm Sci 2000; 12:31-40.

126. Benet LZ, Cummins CL: The drug efflux metabolism alliance: biochemical aspects. Adv Drug Deliv Rev 2001;50:S3-S11.

127. Lown KS, Bailey DG, Fontana RJ, Janardan SK, Adair CH, Fortlage $\mathrm{MB}$, et al: Grapefruit juice increases felodipine oral availability in humans by decreasing CYP 3A protein expression. JClin Invest 1997;99:2545-253.

128. Trausch B, Oertel R, Richter K, Gramatte T: Disposition and bioavailability of the $\beta_{1}$-adrenoceptor antagonist talinolol in man. Biopharm Drug Disp 1995;16:403-414.

129. Milne RJ, Buckley MT: Celprolol: an updated review of its pharmacokinetic properties and therapeutic efficacy in cardiovascular diseases. Drugs 1991;41:941-969.
130. Gottesman MM, Pastan I: Biochemistry of multidrug resistance mediated by the multidrug transporter. Annu Rev Biochem 1993; 62:386-427.

131. Dudeja PK, Anderson KM, Harris JS, Buckingham L, Coon JS: Reversal of multidrug resistance phenotype by surfactants: relationship to membrane lipid fluidity. Arch Biochem Biophys 1995;319: 309-315.

132. Salphati L, Benet LZ: Modulation of P-glycoprotein and expression by cytochrome $\mathrm{P} 4503 \mathrm{~A}$ inducers in male and female rat livers. Biochem Pharmacol 1998;55:387-395.

133. Sparreboom A, Van Asperen J, Mayer U, Schinkel AH, Smit JW, Meijer DKF, et al: Limited oral bioavailability and active epithelial excretion of paclitaxel (Taxol) caused by P-glycoprotein in the intestine. Proc Nat Acad Sci 1997;94:2031-2035.

134. Hoffmeyer S, Burk O, von Richter O, Arnold HP, Rockmoller J, Johne A, et al: Functional polymorphisms of the human multidrug-resistance gene: multiple sequence variations and correlation of one allele with P-glycoprotein expression and activity in vivo. Proc Nat Acad Sci 2000;97:3473-3478.

135. Lo Y-L, Huang J-D: Effects of sodium deoxycholate and sodium caprate on the transport of epirubicin in human intestinal epithelial Caco2 cell layers and everted gut sacs of rats. Biochem Pharmacol 2000;59:665-672

136. Yamazaki T, Sato Y, Hanai M, Mochimaru J, Tsujino I, Sawada U, et al: Non-ionic detergent Tween 80 modulates VP-16 resistance in classical multidrug resistant K562 cells via enhancement of VP-16 influx. Cancer Lett 2000;149:153-161.

137. Woodcock DM, Jeffeerson S, Linsenmeyer ME, Crowther PJ, Chojnowski GM, Williams B, et al: Reversal of the multidrug resistance phenotype with cremophor EL, a common vehicle for water-insoluble vitamins and drugs. Cancer Res 1990;50:4199-4203.

138. Chang T, Benet LZ, Hebert MF: The effect of water-soluble vitamin E on cyclosporin pharmacokinetics in healthy volunteers. Clin Pharmacol Ther 1996;59:297-303.

139. Squier TC, Bigelow DJ, Thomas DD: Lipid fluidity directly modulates the overall protein rotational mobility of the Ca-ATPase in sarcoplamsic reticulum. J Biol Chem 1988;263:9178-9186.

140. Doulder JH, Zimmer G, Woodcock BG, Bockhorn H, Bickeboller $\mathrm{R}$, Schuldes H: Resistance modulation in CHO cells by R-verapamil and bile salts is associated with physical and chemical changes in the cell membrane. Int J Clin Pharmacol Ther 2000;38:196-203.

141. Regev R, Assaraf YG, Eytan GD: Membrane fluidization by ether, other anesthetics, and certain agents abolishes P-glycoprotein ATPase activity and modulate efflux from multidrug-resistant cells. Eur J Biochem 1999;259:18-24.

142. Schuldes H, Dolderer JH, Zimmer G, Knobloch J, Bickeboller R, Jonas D, et al: Reversal of multidrug resistance and increase in plasma membrane fluidity in CHO cells with R-verapamil and bile salts. Eur J Cancer 2001;37:660-667.

143. Martel F, Grundemann D, Calhau C, Schomig E: Apical uptake of organic cations by human intestinal Caco-2 cells: putative involvement of ASF transporters. Naunyn-Schmiedeberg's Arch Pharmacol 2001;363:40-49.

144. Phan CT, Tso P: Intestinal lipid absorption and transport. Front Biosci 2001;6:299-319.

145. Chen M, Yang Y, Braunstein E, Georgeson K, Harmon CM: Gut expression and regulation of FAT/CD36: possible role in fatty acid transport in rat enterocytes. Am J Physiol Endocrinol Metab 2001;281:E916-E923. 
146. Chow SL, Hollander D: A dual, concentration-dependent absorption mechanism of linoleic acid by rat jejunum in vitro. J Lipid Res 1979;20:349-356.

147. Shen H, Howles P, Tso P: From interaction of lipidic vehicles with intestinal epithelial cell membranes to the formation and secretion of chylomicrons. Adv Drug Deliv Rev 2001;50:S103-S125.

148. Lu K, Lee M-H, Patel SB: Dietary cholesterol absorption: more than just bile. Trends in Endocrinol Metab 2001;12:314-320.
149. Thurnhofer H, Hauser H: Uptake of cholesterol by small intestinal brush border membrane is protein-mediated. Biochemistry 1990;29:2142-2148.

150. Ross E: Intestinal absorption of triglyceride and cholesterol: dietary and pharmacological inhibition to reduce cardiovascular risk. Atherosclerosis 2000;151:357-379.

151. Berge KE, Tian H, Graf GA, Yu L, Grishin NV, Schultz J, Kwiterovich P, et al: Accumulation of dietary cholesterol in sitosterolemia caused by mutations in adjacent ABC transporters. Science 2000;290:1771-1775. 